\title{
Biocide Selective TolC-Independent Efflux Pumps in Enterobacteriaceae
}

\author{
Carmine J. Slipski ${ }^{1}$ - George G. Zhanel $^{1} \cdot$ Denice C. Bay $^{1}$
}

Received: 10 July 2017/ Accepted: 4 October 2017/Published online: 23 October 2017

(C) The Author(s) 2017. This article is an open access publication

\begin{abstract}
Bacterial resistance to biocides used as antiseptics, dyes, and disinfectants is a growing concern in food preparation, agricultural, consumer manufacturing, and health care industries, particularly among Gram-negative Enterobacteriaceae, some of the most common community and healthcare-acquired bacterial pathogens. Biocide resistance is frequently associated with antimicrobial crossresistance leading to reduced activity and efficacy of both antimicrobials and antiseptics. Multidrug resistant efflux pumps represent an important biocide resistance mechanism in Enterobacteriaceae. An assortment of structurally diverse efflux pumps frequently co-exist in these species and confer both unique and overlapping biocide and antimicrobial selectivity. TolC-dependent multicomponent systems that span both the plasma and outer membranes have been shown to confer clinically significant resistance to most antimicrobials including many biocides, however, a growing number of single component TolC-independent multidrug resistant efflux pumps are specifically associated with biocide resistance: small multidrug resistance (SMR), major facilitator superfamily (MFS), multidrug and toxin extruder (MATE), cation diffusion facilitator (CDF), and proteobacterial antimicrobial compound efflux (PACE) families. These efflux systems are a growing concern as they are rapidly spread between members of Enterobacteriaceae on conjugative plasmids and mobile genetic elements, emphasizing their importance to antimicrobial
\end{abstract}

Denice C. Bay

Denice.Bay@umanitoba.ca

1 Department of Medical Microbiology and Infectious Diseases, University of Manitoba, Rm 514C Basic Medical Sciences Bldg., 745 Bannatyne Avenue, Winnipeg, MB R3E 0J9, Canada resistance. In this review, we will summarize the known biocide substrates of these efflux pumps, compare their structural relatedness, Enterobacteriaceae distribution, and significance. Knowledge gaps will be highlighted in an effort to unravel the role that these apparent "lone wolves" of the efflux-mediated resistome may offer.

Keywords Efflux pump · Biocide · Multidrug resistance · Quaternary ammonium compound · Multidrug transporter . Antimicrobial resistance

\section{Introduction}

Biocides describe a chemically diverse range of antimicrobial compounds used as antiseptics, disinfectants, and preservatives. In an effort to eradicate potentially infectious bacteria from food preparation, healthcare, and veterinary facilities, biocides such as benzalkonium, chlorhexidine, and triclosan, are commonly used to disinfect exposed surfaces (Gebel et al. 2013), equipment/tubing (Otter et al. 2015), skin, sutures, and wounds (Maillard 2005; Atiyeh et al. 2009). Biocides at high concentrations generally act by disrupting cell envelopes (Maillard 2002; Gilbert and Moore 2005); biocide concentrations (0.1-10\% $\mathrm{w} / \mathrm{v})$ required for disinfection are too toxic for safe ingestion (orally or parenterally) in most human/animal treatments. Many biocide molecules insert between phospholipid headgroups and displace divalent cations, destabilizing the membrane and reducing osmoregulation (Gilbert and Moore 2005). In contrast to therapeutic antibiotics, biocides have far fewer usage regulations (Levy 2002; Maillard 2005), and are common additives in a wide range of products beyond the healthcare/veterinary setting including: cleansers used in meat/dairy facilities, 
household products in cosmetics, apparel, wound dressings, and in water/oil pipeline industries to name only a few (McDonnell and Russell 1999; Chapman 2003a; Gilbert and Moore 2005; Atiyeh et al. 2009). Annual biocide usage by commercial, agricultural, and medical industries combined is estimated to reach and exceed annual antimicrobial usage (Van Boeckel et al. 2014), and contributes to contamination of wastewater and soil sediments [as reviewed by (Tezel and Pavlostathis 2011)]. When environmental biocide concentrations accumulate, selective pressure is believed to drive commensal and pathogenic bacterial adaptation and/or acquisition of biocide resistance mechanisms that degrade (Gilbert and McBain 2003) and/or reduce biocide permeability (Levy 2002; Chapman 2003a).

Biocide resistance among Gram-negative Enterobacteriaceae is particularly concerning, since biocide resistance has demonstrated cross-resistance to a variety of antimicrobials (Chapman 2003b; Braoudaki and Hilton 2004; Gnanadhas et al. 2013), including polymyxins (Wand et al. 2017), which may represent a last line of defense. Since Enterobacteriaceae can spread and thrive in wastewater, sewage, and soils beyond their enteric niches (Szmolka and Nagy 2013), biocide adaptation and chronic low-level exposure in these habitats may be promoting antimicrobial cross-resistance (Gaze et al. 2013; Buffet-Bataillon et al. 2016). Enterobacteriaceae are highly adept at acquiring both biocide and antimicrobial resistance genes (Pal et al. 2015), such as extended spectrum beta lactamases (ESBL), through horizontal gene and conjugative element transfer in the gastrointestinal tract (Stecher et al. 2012), or within the environment (Gaze et al. 2005, 2011).

By comparison to Gram-positive bacteria, Gram-negative bacteria have higher tolerance to antimicrobials including biocides due to the architecture and composition of their cell envelope that possesses a lipopolysaccharide rich outer membrane, reducing permeability (Fig. 1a). Biocide resistance in Gram-negative Enterobacteriaceae is associated with an assortment of cell envelope alterations that reduce antimicrobial permeability: lipid modifications (Ishikawa et al. 2002; Gilbert and Moore 2005), porindown regulation (Fernandez and Hancock 2012), outer membrane vesicle formation (Jagannadham and Chattopadhyay 2015; Kulkarni et al. 2015), and intrinsic efflux pump up regulation or efflux pump acquisition (Poole 2002, 2014b; Blair et al. 2014). Among all of these diverse resistance mechanisms, efflux pump activity is a major contributor, particularly in Enterobacteriaceae, due to the presence and diversity of many efflux systems with overlapping (redundant) substrate recognition, and drug polyspecificity. Efflux poses complex resistance challenges to overcome therapeutically, since a single efflux pump can expel a variety of chemically diverse biocides and antimicrobials from the cell. Enterobacterial genomes can encode more than four different efflux pump families on average (Fig. 1b), and many of these families have close homology to eukaryotic transporter protein families (Saier, Jr and Paulsen 2001; Saier et al. 2016), making efflux a formidable resistance mechanism to inhibit (Marquez 2005; Baugh et al. 2014; Opperman and Nguyen 2015).

In Escherichia coli, efflux-mediated resistance to antimicrobials is conferred by multipartite protein efflux pump systems that span the outer membrane (OM), periplasm, and plasma membrane (PM) through a protein complex between an outer membrane protein (OMP), a membrane fusion protein (MFP), and efflux pump protein(s) (Nishino et al. 2003). In general, antimicrobial resistance is conferred mainly by the activity of three multipartite efflux pump transporter families; ATP driven

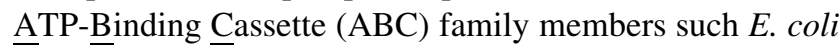
$\overline{\mathrm{Mac}} \overline{\mathrm{AB}}$ system (Poole 2014b; Orelle and Jault 2016), by proton motive force driven Resistance-Nodulation-Cell Division (RND) efflux family members AcrAB (Du et al. 2014), and members of the Major Facilitator Superfamily (MFS) such as EmrAB (Kumar et al. 2013b). In Enterobacteriaceae, these systems rely upon an OMP, TolC, to expel various toxic substrates from the periplasmic space across the OM (Zgurskaya et al. 2011).

In addition to TolC-dependent multipartite efflux pump systems, there have been a growing number of single component, TolC-independent, ion $/ \mathrm{H}^{+}$driven efflux pump families shown to play a supporting or major role in antimicrobial resistance, most notably to biocides. These single component secondary active efflux pumps can all confer biocide resistance in the absence of TolC and belong to a variety of transporter families; the small multidrug resistance (SMR) family (Bay et al. 2008) part of the drug and metabolite transporter (DMT) superfamily (Jack et al. 2001), multidrug and toxin extrusion (MATE) family (Kuroda and Tsuchiya 2009), major facilitator superfamily (MFS) (Saidijam et al. 2006; Yan 2013), cation diffusion facilitator (CDF) family (Fang et al. 2002; Cubillas et al. 2013), and the recently identified proteobacterial antimicrobial compound efflux (PACE) family (Hassan et al. 2013, 2015b). Hence, they are often referred to as TolCindependent efflux systems (Nishino et al. 2003). It is not well understood if TolC-independent efflux pump members function through a single dedicated, but as yet unidentified $\mathrm{OMP}(\mathrm{s})$, or if these efflux systems can utilize a variety of OMPs/channels to completely expel drug substrates from the cell. However, these efflux systems are increasingly important to examine in Enterobacteriaceae based on their ability to confer overlapping substrate specificity, but also resistance to unique substrates not offered by their multipartite system counterparts (Bragg et al. 2014). TolC-independent efflux systems can also expel toxic metabolites 


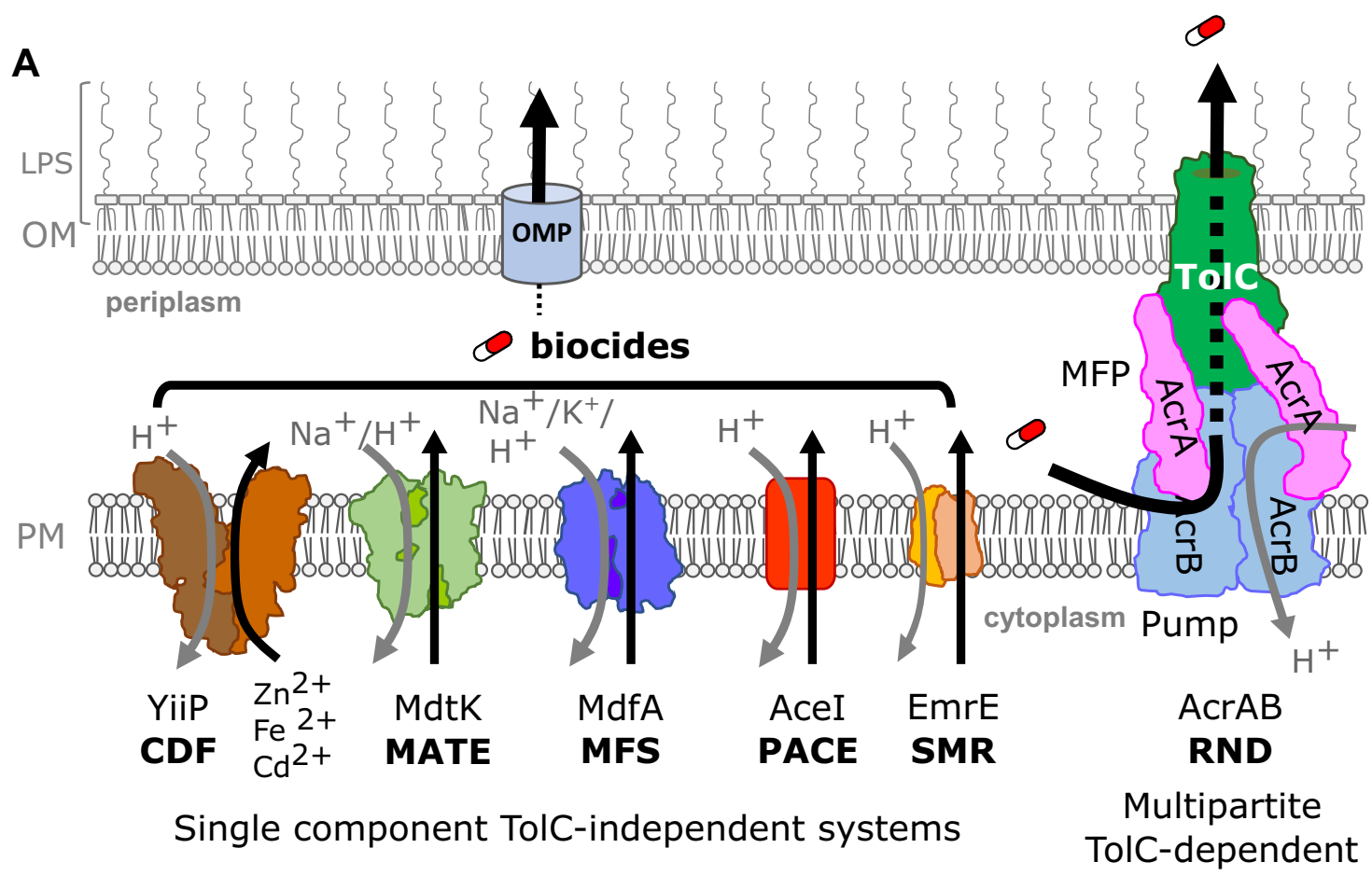

B

Presence of biocide selective efflux pump sequences detected in Enterobacterial genomes

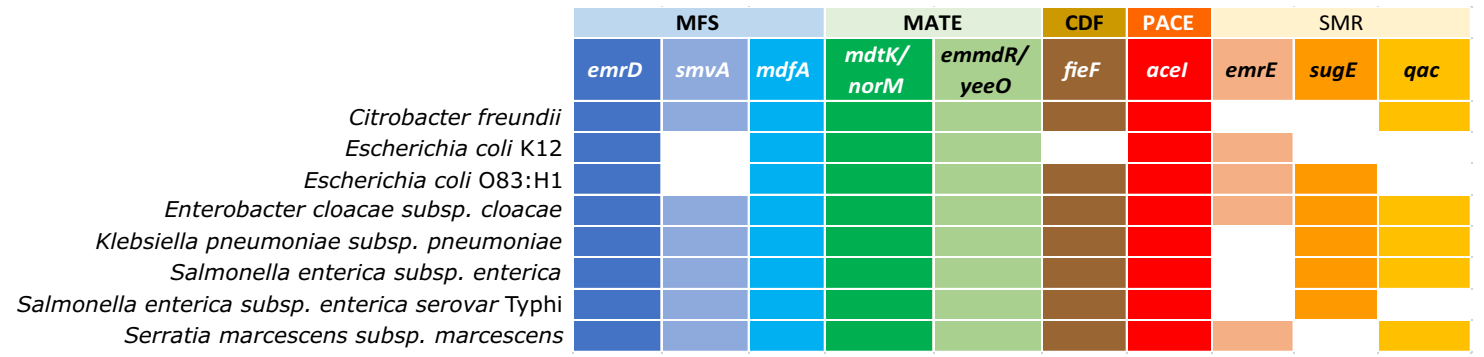

Fig. 1 a Summary diagram of single component TolC-independent biocide selective efflux pump transporter family members in Enterobacteriaceae. TolC-independent archetypical transporter family members generated from their representative crystal structures for each of the five families: CDF dimer structure CepA/FieF/YiiP (PDB 3H90; Lu et al. 2009), MATE MdtK/NorM (PDB 3MKT; He et al. 2010), MFS MdfA (PDB 4ZOW; Heng et al. 2015), PACE AceI, and SMR EmrE (PDB 3B5D Chen et al. 2007) are shown in the plasma membrane alongside a representative RND multipartite system, AcrA, AcrB, and TolC complex (PDB 5066; Wang et al. 2017). Gray

and molecules that may be important for cell communication, biofilm formation, and osmoregulation, enhancing their roles in virulence (Piddock 2006; Alcalde-Rico et al. 2016). Efflux pump redundancy and overlapping substrate specificity are some of the major hurdles in elucidating specific efflux pump substrate profiles and in designing improved specific efflux pump inhibitors (Stavri et al. 2007; Tegos et al. 2011). Since many single component efflux pumps are conditionally expressed (Tal and arrows indicate the direction of ion influx and black arrows show the direction of substrate efflux. b A distribution heatmap of TolCindependent efflux pump members within various Enterobacterial genera. Characterized efflux pumps from various Enterobacteriaceae listed in Table 1 were used as query sequences to detect the presence of each member within the completed Enterobacterial genome sequences using tBLASTn (Gertz et al. 2006). The presence (filled squares) and absence (white squares) of efflux pump gene sequences within more than $75 \%$ of the listed Enterobacterial species is indicated

Schuldiner 2009; Hassan et al. 2015a), and are frequently encoded on mobile genetic elements including multidrug resistant plasmids, they are of particular importance to consider in our efforts to combat efflux-mediated multidrug resistance.

Because there have been a number of excellent recent review articles summarizing antimicrobial resistance attributed to multipartite TolC-dependent efflux systems (Poole 2014b; Sun et al. 2014; Li et al. 2015), this article 
will overview biocide resistance from the perspective of single component, TolC-independent, secondary active efflux pump systems in Enterobacteriaceae, specifically members of the SMR, MFS, MATE, CDF, and PACE families. The aim of this review is to provide an overview of biocides targeted by single component efflux systems, by comparing the biocide and antimicrobial selectivity of characterized members of Enterobacteriaceae, highlight the shared and unique structural features of these pumps, and summarize the significance of their individual activities on resistance and virulence. The knowledge gaps regarding single component efflux pumps conferring biocide resistance will be also discussed in the concluding remarks.

\section{Biocide Substrates of Single Component Secondary Active Efflux Pumps}

Single component efflux pumps have garnered criticism regarding their clinical significance and contributions to biocide resistance as well as antimicrobial resistance (Russell 2003; Sheldon Jr. 2005; Hirsch et al. 2011), largely due to their modest minimal inhibitory concentration value increases and lower activity when compared to multipartite efflux systems (Russell 2000; Poole 2002; Hegstad et al. 2010). Identification of specific biocide substrates attributed to specific single component efflux pumps is challenging due to the presence of multiple efflux pump families in any given member of Enterobacteriaceae (Fig. 1b). BLAST-based surveys involving characterized single component efflux members within Enterobacteriaceae genomes reveals that most species possess at least three of the five families discussed herein (Figs. 1b and 2). Single efflux pump gene deletions in Enterobacteriaceae often fail to accurately identify the full range of substrates they may recognize due to the presence of the dominant multicomponent RND system, AcrAB (Sulavik et al. 2001; Tal and Schuldiner 2009). Hence, substrate determination for single component secondary active efflux pumps are commonly determined by pump overexpression in $E$. coli strains lacking $a c r B$, such as KAM3 and KAM32 (Chen et al. 2002), to avoid competition with the AcrAB system (Table 1). Single component efflux pumps have been reported to confer resistance to a wide range of chemically diverse biocides and other classes of antimicrobials as shown for MFS and MATE family members (Table 1). In contrast, some pumps demonstrate a preference for one specific class of biocide over others (Table 1). SMR family members confer resistance to a broad range of antiseptics, and relatively few antibiotics (Bay et al. 2008), while CDF member CepA/FieF appears to confer significant resistance to chlorhexidine (Fang et al. 2002) (Table 1). Some of the problems with comprehensive substrate identification are broad range of biocides to include in susceptibility testing and the lack of standard biocide testing methods as noted in a number of reviews over the last two decades (McDonnell and Russell 1999; Gilbert and McBain 2003; Gilbert and Moore 2005; Tumah 2009; Buffet-Bataillon et al. 2012).

Antiseptics (benzalkonium, cetrimide, and cetylpyridinium), herbicides (methyl viologen), and dyes (ethidium, acriflavine, and rhodamine $6 \mathrm{G}$ ) that have one or more permanently charged cationic atoms, typically nitrogen, are referred to as quaternary ammonium compounds (QACs) (Gilbert and Moore 2005; Zhang et al. 2015). QACs appear to be the most common substrate of single component efflux pumps as highlighted in Table 1. In fact, ethidium or Hoechst 33342 are QAC dyes commonly used to identify and validate the activity of most TolC-independent efflux pumps (Blair and Piddock 2016). QACs are also one of the most heavily used biocides with an estimated global usage of 700 kT/year; (Tezel and Pavlostathis 2011), as these compounds are routine additives to commercial, industrial, agricultural, livestock, veterinary, and healthcare products (Zhang et al. 2015).

In contrast, resistance to the bisbiguanide antiseptic chlorhexidine appears to be highly selective and somewhat inconsistent as a substrate for many Enterobacteriaceae efflux pump families, particularly CDF and PACE (Hassan et al. 2015b). Chlorhexidine is commonly added to medical solutions, wipes, baths, and cleansers in medical and veterinary facilities. This apparent bias in substrate selectivity may have as much to do with the inconsistent inclusion of biocide chemicals in routine resistance screening panels, as it does with their over-usage in commercially available products.

It is important to note that the antiseptic triclosan, a chlorinated phenoxyphenol used in oral hygiene products and cleansers, does not appear to be a substrate of single component efflux systems to date (Minato et al. 2008; He et al. 2011a, b). Triclosan is a substrate of multipartite AcrAB systems in E. coli (McMurry et al. 1998), and Salmonella spp. (Webber et al. 2008) and the unique multipartite system TriABC-OmpH in Pseudomonas spp. (Mima et al. 2007). Triclosan resistance is also conferred due to lipid modification; triclosan binds and inhibits the activity of the fatty acid biosynthesis gene $f a b I$, an enoylacyl carrier protein (Sivaraman et al. 2004). A similar situation is noted for the antiseptic polyhexamethylene biguanide (PMHB), a biguanide used in skin wound care products and ointments, which appears to be a substrate of the multipartite MexCD-OprJ RND system (Fraud et al. 2008).

Cationic biocides like QACs and chlorhexidine function by disrupting the outer and inner plasma membranes of Gram-negative bacilli, denaturing proteins, and enhancing reactive oxygen and nitrogen species generation (Gilbert 
Fig. 2 A summary of the average distance percent efflux pump protein family members identified from Enterobacterial genomes. The dendrogram was generated using Jalview software (Waterhouse et al. 2009) based on protein sequence alignments of efflux pump sequences (shown according to GenBank locus tag or protein accession K12 (b), E. coli O83:H1 str. NRG 857C, Enterobacter cloacae (ECL), Salmonella enterica subsp. enterica serovar Typhi str. CT18 (STY), Citrobacter freundii CFNIH1, Klebsiella pneumoniae subsp. Protein sequence percent identities were generated from a pairwise alignment was generated using ClustalW BLOSUM weight matrix and bootstrapping of the generated tree matrix was performed using the ' $R$ ' statistics software "boot" package (Ripley 2017). Bootstrap $p$-values of $<80 \%$ are indicated above each node with a black circle, and $p$-values ranging from 79 to $65 \%$ are indicated by gray circles identities of TolC-independent numbers) collected from $E$. coli pneumoniae (KPHS) species.

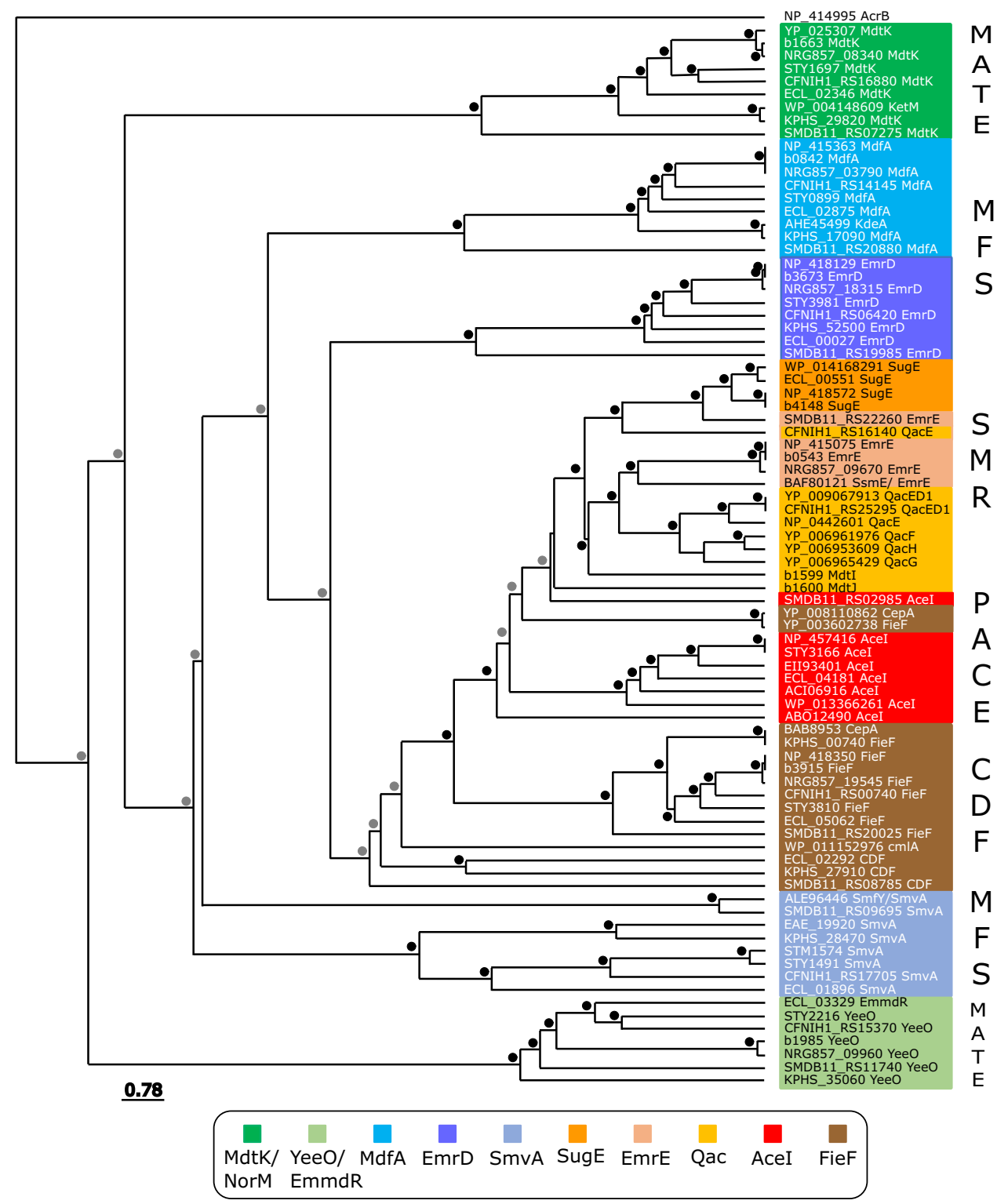

and Moore 2005). Currently, it remains unclear how efflux pumps can target and expel biocides without succumbing to the effects of the biocide itself, since cationic biocides have the propensity to disrupt membranes at low concentrations and dissipate proton motive force. This phenomenon may explain why many efflux pumps listed in Table 1 confer modest (1-sixfold) increases in biocide MICs. Experiments have demonstrated that the inhibition of efflux systems using electron transport chain disrupting compounds such as CCCP reduce biocide tolerance in Enterobacteriaceae (Braoudaki and Hilton 2005; Rania et al. 2014). Some of the structural features that unify biocide resistance pumps is their increased hydrophobicity and the involvement of negatively charged residues in active site regions of the protein that bind drugs as discussed in the following sections. SMR members have demonstrated a requirement for anionically charged phospholipids, such as cardiolipin and phosphatidyl glycerol (Charalambous et al. 2008; Miller et al. 2009; Dutta et al. 2014), suggesting that the membrane environment may also play an important contribution for biocide recognition and resistance. More studies involving structural and functional analysis of single component efflux pump systems summarized herein will be important in understanding how efflux pumps recognize and transport biocides and other antimicrobial compounds. 


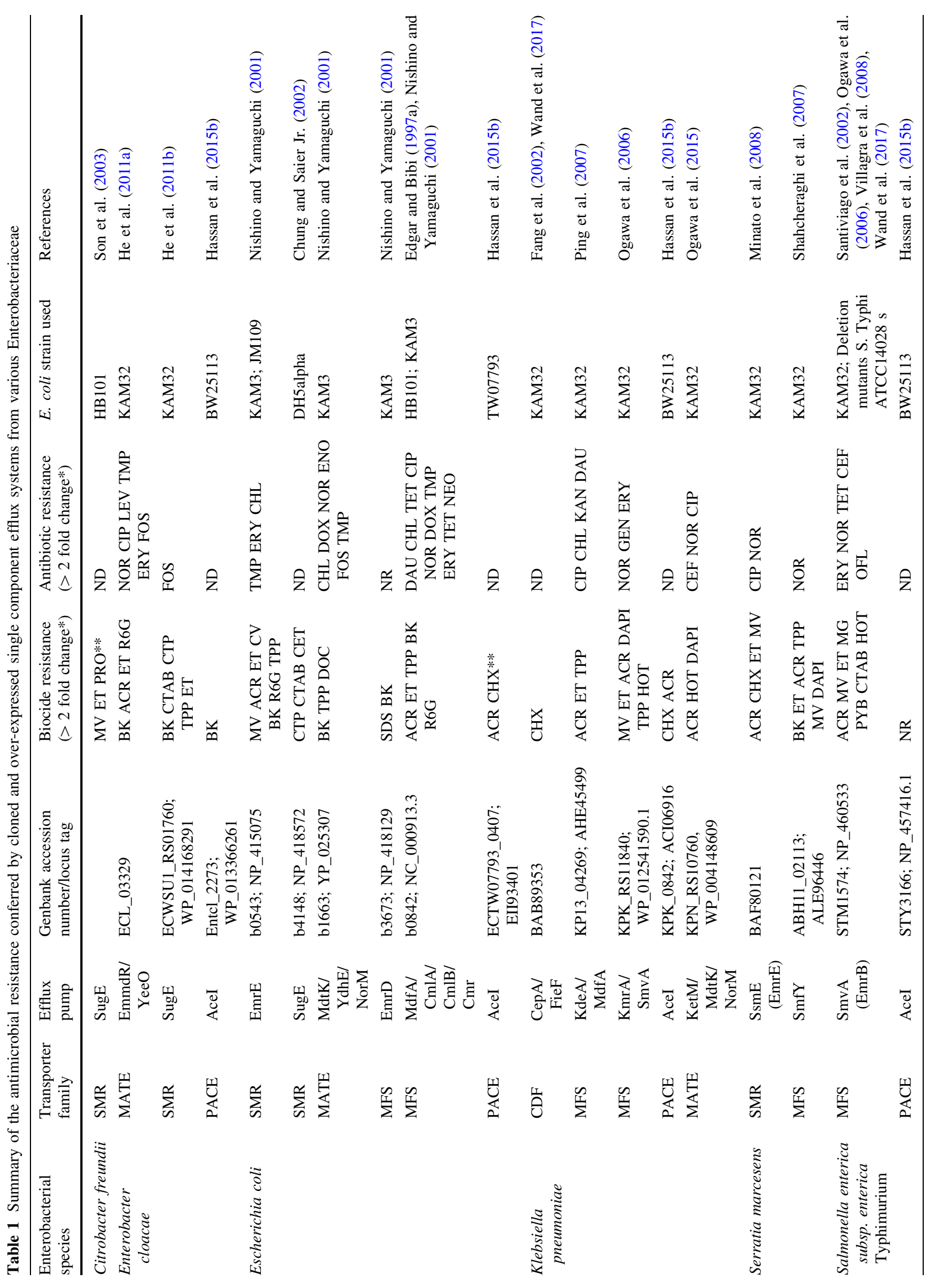




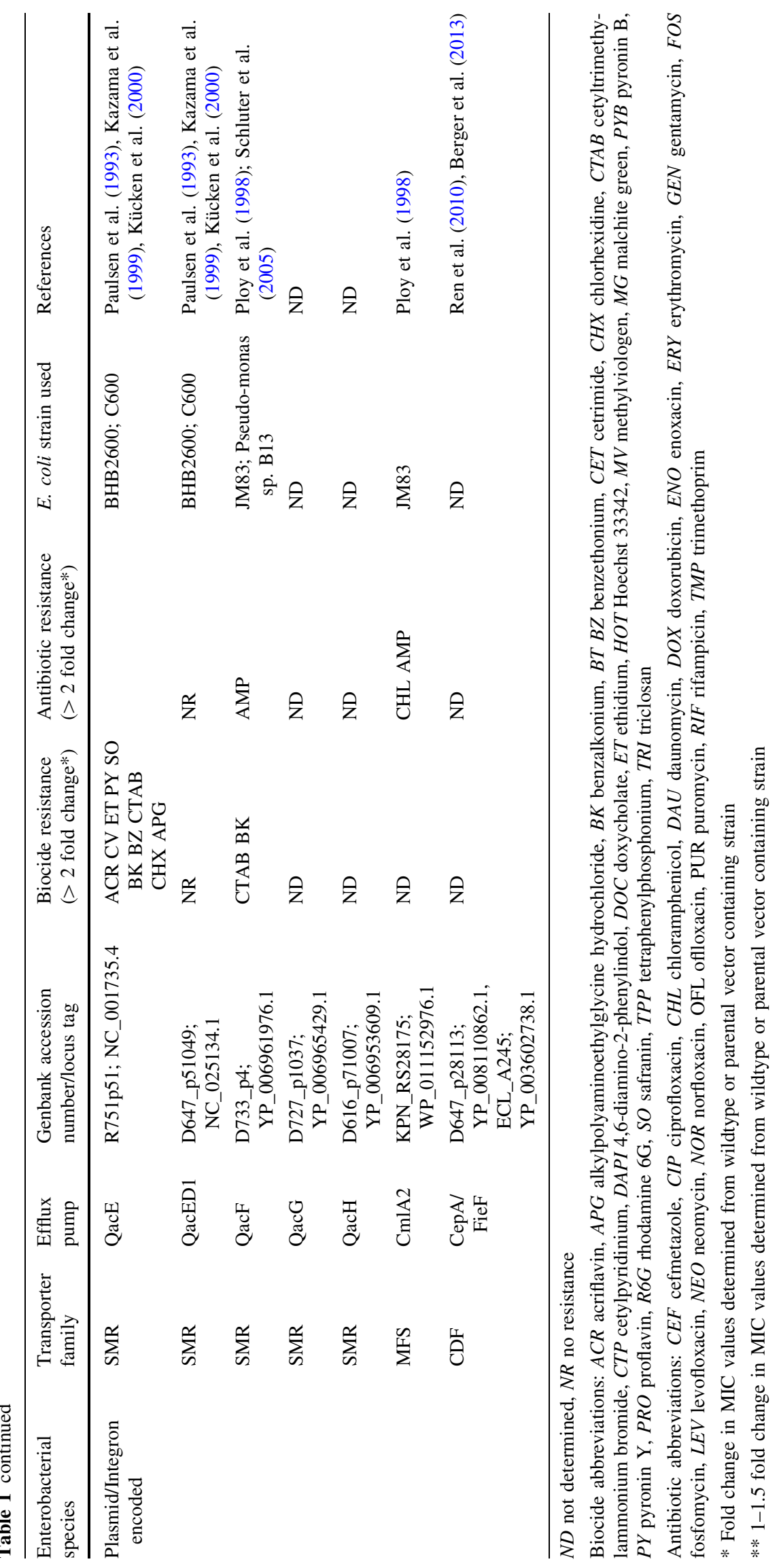




\section{Small Multidrug Resistance (SMR) Efflux Family}

SMR protein family members represent one of the smallest efflux families to date, are exclusive to Bacterial and Archaeal kingdoms, and range in length from 100 to 140 amino acids (Bay et al. 2008). SMR genes are inherited vertically on the chromosome, but are frequently encoded by prophages (Wang and Wood 2016), Class 1 and Class 3 integrons (Gaze et al. 2005), and conjugative multidrug resistance plasmids (Bay and Turner 2009) (Table 1; Fig. 1b). The most well characterized and archetypical member of the SMR family is E. coli ethidium multidrug resistance protein $\mathrm{E}$ (EmrE). At only 110 amino acids in length $(12 \mathrm{kDa})$, EmrE consists of four transmembrane $\alpha$ helical TMH domains that arrange to form a minimal homodimeric functional unit (Butler et al. 2004; Dutta et al. 2014) (Fig. 3a). The topological arrangement of EmrE monomers within the dimer has been controversial (Schuldiner 2010), as EmrE protein monomers have demonstrated functional activity when both amino and carboxy termini face the same direction (Steiner-Mordoch et al. 2008) or in an asymmetrical arrangement where termini face opposite sides of the membrane (Korkhov and Tate 2009; Morrison et al. 2011; Lloris-Garceras et al. 2012). At the present time, experimental consensus supports an asymmetric SMR dimer topology for the EmrE protein. All SMR members possess a single highly conserved negatively charged glutamate residue (E. coli EmrE E14) within the first TMH which participates in both $\mathrm{H}^{+}$ and drug binding during transport (Morrison et al. 2015) (Fig. 3a). Despite their small size, SMR members are capable of transporting relatively large cationic compounds, primarily QACs and a limited range of antimicrobials (Table 1), similar to much larger MFS and MATE transporters (12-14 TMH). SMR efflux proteins can be classified into three subgroups, small multidrug protein (SMP); suppressor of groEL (SUG); and paired SMR proteins (PSMR) based on phenotypic and phylogenetic sequence analysis (Bay et al. 2008; Bay and Turner 2009, 2016).

The SMP subgroup confers resistance to a wide range of QACs when expressed as a single gene (refer to references provided in Table 1), and SMP members include homologues of E. coli EmrE. SMP members may also participate in osmotic regulation, as E. coli EmrE overexpression results in hypersaline and $\mathrm{pH}$ related loss of growth phenotypes due to the loss of osmoprotectants, specifically betaine and choline (Bay and Turner 2012). In addition to EmrE homologues, SMP subgroup members include integron and multidrug resistant plasmid encoded quaternary ammonium compound resistant proteins (Qac) that also confer resistance to a broad range of QACs (Bay et al.
2010; Buffet-Bataillon et al. 2012). A number of Qac members have been identified in Enterobactericaeae, QacE, QacE $\Delta 1$, QacF, QacG, and QacH; where the most frequently identified qac gene from multidrug resistant clinical (Kücken et al. 2000; Wang et al. 2008; PastranaCarrasco et al. 2012) and food contaminant (Zou et al. 2014; Zhang et al. 2016) genetic surveillance studies is qacE 11 . QacE $\Delta 1$ has demonstrated poor QAC efflux activity $(30 \%)$ in comparison to QacE based on overexpression experiments (Paulsen et al. 1993; Kazama et al. 1999); QacE $\Delta 1$ and QacE are nearly identical (up to residue 94), and differ by an in-frame insertion element that disrupts and extends the fourth $\mathrm{TMH}$ of QacE $\Delta 1$ by an additional five amino acids. It is uncertain why a semifunctional qacE $\Delta 1$ is so highly conserved on $3^{\prime}$ regions of Class 1 integrons when compared to other Qac members including qacE. The activity of qacE $\Delta 1$ may improve cross-resistance conferred by its synergy to other conserved resistance genes in the $3^{\prime}$ region including sulfonamide (sull), adenylyltransferase ( $a a d)$, and dihydrofolate reductase ( $d f r A$ ) (Mazel et al. 2000; Su et al. 2006; Gillings et al. 2008); further studies would help clarify its importance. Qac member detection is highly correlated to QAC contaminated areas (Gaze et al. 2011) and serves as a useful marker for QAC biocide pollution (Gaze et al. 2005). Many qac genes frequently detected in pathogenic Enterobacteriaceae are also identified from environmentally isolated Enterobacterial biofilms (Gillings et al. 2009), where acquiring one or more Qac members may confer selective advantages such as an ability to expel toxic and QAC-based metabolic compounds as demonstrated by other SMR members.

Members of the SUG subclass are phylogenetically distinct from SMP members (Bay and Turner 2009), and were originally named for their ability to suppress groEL chaperonin protein $\mathrm{E}$ (SugE) in E. coli that was later demonstrated to be a cloning artifact (Bishop and Weiner 1993; Bishop et al. 1995). Characterized SUG members include SugE from E. coli and Citrobacter freundii, where E. coli SugE members have demonstrated resistance to a narrow range of long acylated QACs, including cetrimide and cetylpyridinium (Chung and Saier Jr. 2002). Resistance to other metal containing biocides has also been demonstrated by Gram-negative Aeromonas molluscorum SugE homologs that specifically efflux di- and tri-butyltin (Cruz et al. 2013); tin containing biocides banned from use in developed countries since the 1990s. Mutational studies of C. freundii Sug members can demonstrate function as an importer as well as an exporter (Son et al. 2003), similar to EmrE (Brill et al. 2012). A recent biofilm study of E. coli single gene deletion mutants identified that a $\operatorname{sug} E$ deletion enhanced biofilm biomass formation, suggesting that under wildtype conditions this pump may expel metabolites 
Fig. 3 Topology diagrams of biocide resistant efflux pumps representing transporter families SMR, MFS, MATE, CDF, and PACE. a Topology diagram of SMR member E. coli EmrE (NP_415075); this protein inserts in either orientation, therefore, no membrane orientation is shown.

b Topology diagram of MFS member E. coli MdfA (NP_415363). c Topology diagram of MATE member E. coli $\mathrm{MdtK} / \mathrm{NorM} / \mathrm{YdhE}$ (YP_025307). d Topology diagram of PACE member E. coli (EII93401). e Topology diagram of CDF member E. coli FieF/YiiP (NP_418350).

Topology diagrams were generated using the web interface program Protter version 1.0 (Omasits et al. 2014)

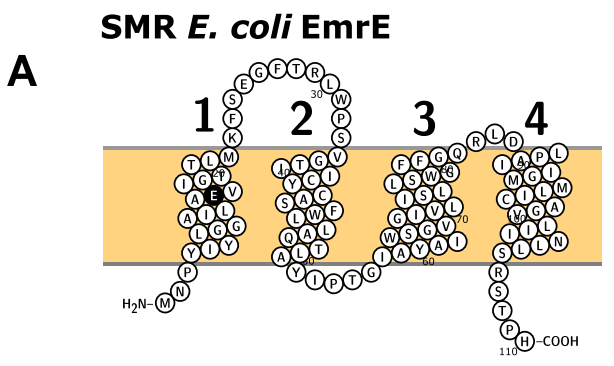

PACE E. coli AceI

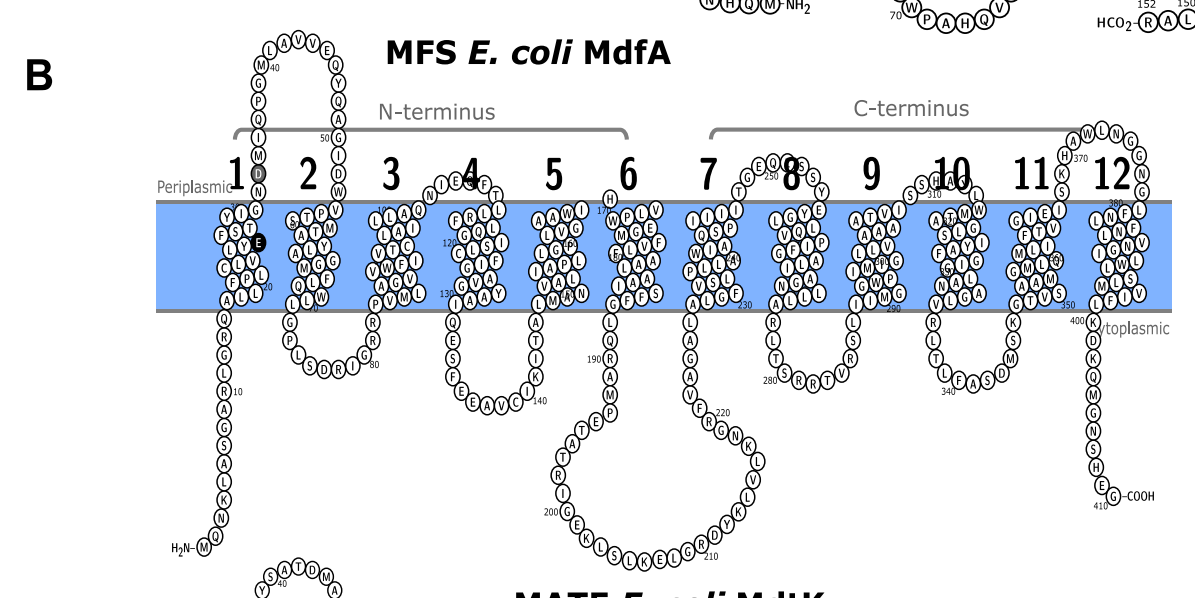

C

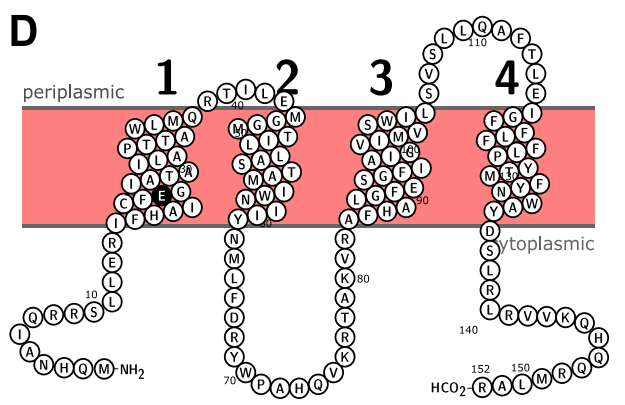

E
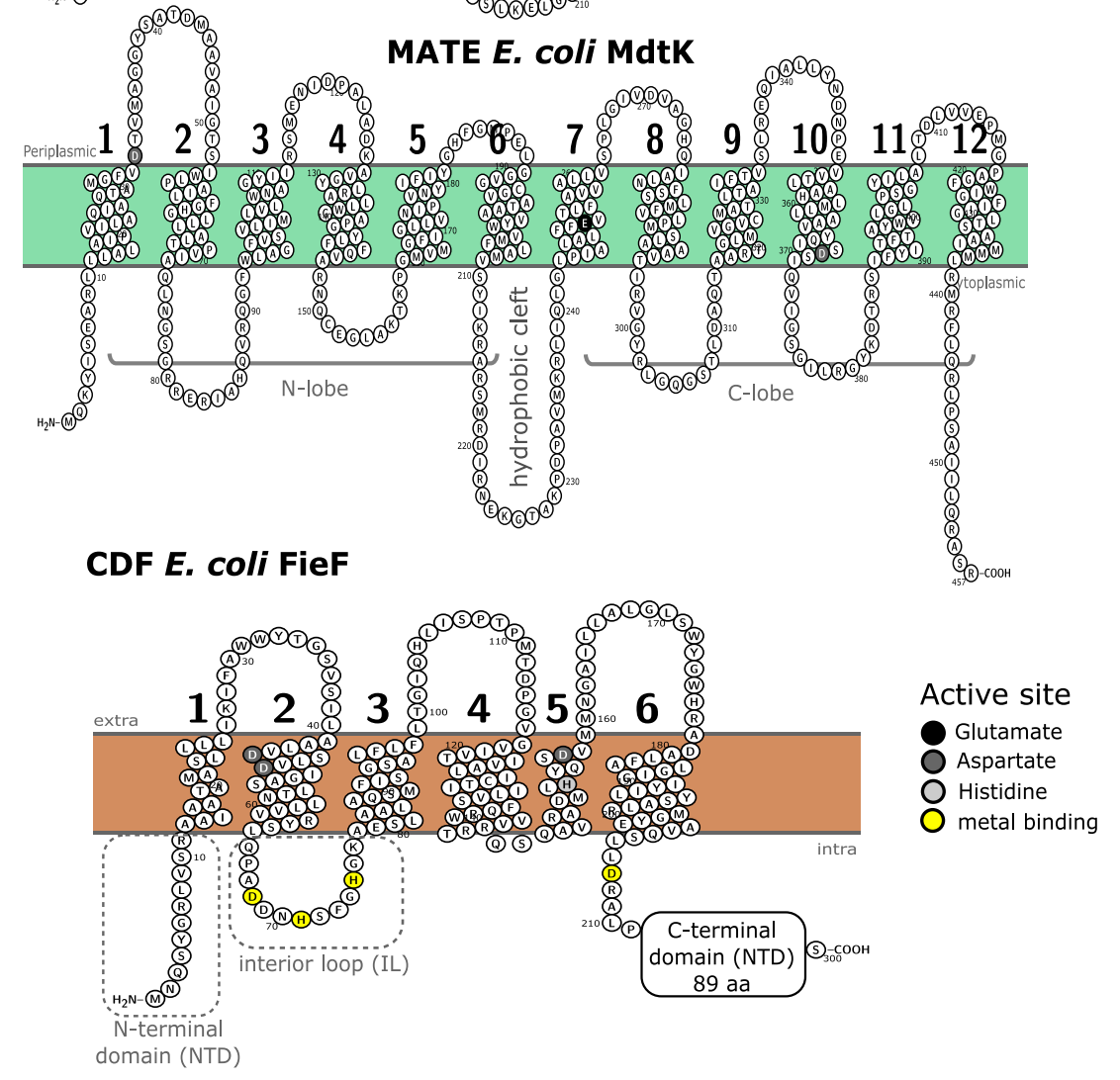

regulating biofilm formation (Bay et al. 2017). Although SUG members are inherited chromosomally, many Enterobacteriaceae SugE homologs are detected from mobile genetic elements carried on multidrug resistant plasmids, particularly in the poultry industry (Chung and Saier Jr. 2002; Hegde et al. 2016). This suggests that SMR 
members, such as SUG and SMP Qac proteins, may be selectively enriched either on specific mobile genetic elements or by QAC pollution (Gaze et al. 2005).

The PSMR subclass differs from SMP and SUG subgroups due to the expression of two distinct genes to confer QAC resistance forming a functional heterodimer (Bay et al. 2008). Phylogenetic analysis of PSMR subgroup homologues indicates that these proteins evolved more recently due to gene duplications from SMP and SUG group members, however, in Enterobacteriaceae PSMR members share close homology to E. coli MdtIJ (YdgEF) related to the SMP subclass (Bay and Turner 2009). By comparison to EmrE, PSMR proteins have longer hydrophobic loops between TMH1-4 and an extended carboxyl-terminus (Kikukawa et al. 2007), that fixes their topology and multimerization into asymmetric heterodimers (Drew et al. 2002; Rapp et al. 2004). While MdtIJ does confer multidrug resistance to QACs and cationic dyes, they also contribute towards polyamine resistance indicating they may play an important role in preventing polyamine toxicity (Higashi et al. 2008).

\section{Major Facilitator Superfamily (MFS) Efflux Family}

MFS transporters span all three kingdoms of life and currently form 74 families (Reddy et al. 2012). In Enterobacteriaceae, characterized MFS members that are capable of conferring biocide resistance include the TolCdependent multipartite efflux pumps systems; E. coli EmrKY and EmrAB (Li and Nikaido 2004; Tanabe et al. 2009), and TolC-independent as well as monomeric TolCindependent efflux pumps: EmrD (Naroditskaya et al. 1993; Nishino and Yamaguchi 2001; Yin 2006), and MdfA/CmlA/Cmr (Edgar and Bibi 1997a; Bohn and Bouloc 1998) (Table 1; Figs. 1b, 2). Enterobacteriaceae typically encode two or three different TolC-independent biocide selective MFS members that confer both QAC and fluoroquinolone resistance: EmrD, MdfA, and SmvA (Table 1, Figs. 1b, 2). The third MFS family member known as $\mathrm{SmvA} / \mathrm{KmvA} / \mathrm{SmfY}$ is distinguished for its ability to confer methyl viologen resistance and has been functionally characterized from Salmonella enterica serovar Typhimurim (Hongo et al. 1994; Santiviago et al. 2002; Villagra et al. 2008), Serratia marcescens (Shahcheraghi et al. 2007) and K. pneumoniae (Ogawa et al. 2006) species (Table 1).

MFS members typically range from 400-600 amino acids in length and possess $12 \mathrm{TMH}$ that form two $6 \mathrm{TMH}$ domains at the N- and C- termini (Yan 2013). TolC-independent MFS members from Enterobacteriaceae share close identity to either E. coli $\mathrm{EmrD}$, SmvA, or MdfA as shown in Fig. 2. Enterobacteriaceae monomeric biocide selective efflux pumps belonging to the MFS members generally possess 12 TMH (Fig. 3b), with the exception of Serratia marcescens SmfY (Shahcheraghi et al. 2007) with $14 \mathrm{TMH}$ as noted by (Hofmann and Stoffel 1993; Krogh et al. 2001) and predicted by TMpred and TMHMM. Regardless of TMH number, both $\mathrm{N}$ - and C-termini of MSF generally face the cytosolic side of the membrane, and structural similarity between each $\mathrm{N}$ - and C-terminal domain suggests that the MFS efflux protein originated from a gene duplication event (Saier Jr. 2001; Saier Jr. and Paulsen 2001; Reddy et al. 2012). Monomeric MFS transporters function through two pseudosymmetrical 6 TMH domain units that surround a central hydrophobic substrate binding pocket with fluctuating drug/ion access via a rocker-switch mechanism (Yan 2013; Quistgaard et al. 2016) (Fig. 3b). Most MFS members contain two highly conserved, negatively charged residues in their central substrate binding pocket; in E. coli MdfA the loss of residues E26 and D34 in TMH1 eliminates drug efflux activity (Adler et al. 2004; Sigal et al. 2006). However, in a previous study a pair of glutamates required for drug efflux activity could be removed and replaced in different TMH (Sigal et al. 2009), highlighting the conformational plasticity of these proteins (Fig. 3b). Some studies demonstrate that MFS transporters may utilize $\mathrm{Na}^{+} / \mathrm{K}+$ as well as $\mathrm{H}^{+}$ in drug antiport function (Edgar and Bibi 1997a; Mine et al. 1998; Lewinson et al. 2004). The ability to use $\mathrm{Na}^{+}$ and $\mathrm{H}^{+}$appears to confer an osmoregulatory function for these pumps, as observed for alkali tolerant $E$. coli MdfA and $K$. pneumoniae KdeA/MdfA strains when these pumps are over-expressed (Lewinson et al. 2004; Ping et al. 2007). Alkali tolerance synergizes well with known cationic biocide resistance mechanisms as both are stress induced responses in Enterobacteriaceae [as reviewed by (Rowbury 2003; Poole 2014a; Buffet-Bataillon et al. 2016)].

TolC independent MFS members can be inherited vertically on the chromosome, as demonstrated by E. coli MdfA and EmrD (Edgar and Bibi 1997b; Nishino and Yamaguchi 2001), as well as on mobile genetic elements such as $\mathrm{Cmr} / \mathrm{CmlA}$, which are found on integrons and multidrug resistant conjugative plasmids making them highly transmissible, particularly within environments highly contaminated by QACs (Bohn and Bouloc 1998; Ploy et al. 1998; Heuer et al. 2004; Bischoff et al. 2005). In E. coli, MFS efflux proteins make up about half of all unique efflux transporters known, highlighting their importance for biocide and multidrug resistance (Kumar et al. 2013a). Experiments involving E. coli RND AcrAB pump deletions demonstrated that chromosomally encoded SMR and MFS members, EmrE and MdfA respectively, were important to confer antimicrobial resistance under specific growth conditions (Tal and Schuldiner 2009), 
underscoring their importance in expelling substrates, specifically methyl viologen, a biocide not recognized by RND pumps (Villagra et al. 2008). Expression and deletion of $E$. coli MFS member MdfA has also demonstrated its involvement in enhancement of biofilm formation (Matsumura et al. 2011; Soto 2013b), suggesting it may play a role in biofilm establishment and biocide tolerance. Hence, with multiple copies of TolC-independent MFS members in a single Enterobacteriaceae species, the contributions of these pumps to biocide resistance may be highly important when conditions arise that prohibit RND and other multipartite system activities.

\section{Multidrug and Toxic Compound Extrusion (MATE) Efflux Family}

MATE protein family members are part of the larger multidrug/oligosaccharidyl-lipid/polysaccharide (MOP) superfamily (Hvorup et al. 2003). MATE family members are currently subdivided into three main subfamilies according to kingdom and sequence phylogeny: Family 1 bacterial MATEs; Family 2, eukaryotic MATEs subdivided as 2A fungal, 2B plant, 2C animal, and 2D protozoan; and Family 3, bacterial and archaebacterial MATEs (Omote et al. 2006; Kuroda and Tsuchiya 2009). The first bacterial MATE member, NorM, is related to family 1 and was identified from Vibrio parahaemolyticus (Morita et al. 1998), and has high sequence similarity and homology to MdtK (YdhE) based on its identification in E. coli (Figs. 1b and 2). There is no single archetypical MATE member to date due to the low sequence identity between MATE homologues $(\sim 40 \%)$, which can range in length from 440 to 500 amino acids (Omote et al. 2006). However, NorM crystal structures from Neisseria gonorrhea (Lu et al. 2013) and Vibrio cholerae (He et al. 2010) best represent bacterial MATE transporters at present. Functional $\mathrm{Na}^{+}$ dependency has not been demonstrated for all MATE families (Mishra and Daniels 2013), but bacterial NorM homologues have demonstrated both $\mathrm{Na}^{+}$and $\mathrm{H}^{+}$dependence (Lu et al. 2013; Jin et al. 2014). MATE transporters typically arrange into $12 \mathrm{TMH}$ (Fig. 3c) based on V. cholerae and $N$. gonorrhea NorM crystal structures, forming two lobes at the N- (TMH 1-6) and C- (7-12) terminal domains with a hydrophobic cleft connected by a cytoplasmic loop between TMH 6-7 similar to MFS members (as reviewed by (Kuroda and Tsuchiya 2009; Lu et al. 2013; Du et al. 2015)). Based on the conservation and symmetry within the $\mathrm{N}$ - and C-lobes, each domain within MATE proteins likely arose due to gene duplication or fusion event similar to MFS members ( $\mathrm{Lu}$ et al. 2013). However, a 13th TMH may be present at the C-terminus as suggested by an epitope tagged eukaryotic MATE1 homologue (Zhang and Wright 2009) and hydropathy plots. Similar to SMR and MFS members, functionally essential and highly conserved negatively charged residues serve as active sites for binding cationic drugs and/or ions (Kuroda and Tsuchiya 2009; Du et al. 2015). Negatively charged residues are positioned in both lobes at TMH1 D32, TMH7 E252, and TMH10 D368 (Omote et al. 2006) numbered according to E. coli MdtK (Fig. 2). MATE efflux proteins demonstrate a rotational symmetry within the first and last TMH loops forming the $\mathrm{N}$ and $\mathrm{C}$ lobe domains respectively, and a cytoplasmic loop connects the two halves between TMH loops 6 and 7 (Fig. 2) (He et al. 2010; Nishima et al. 2014). Substrate binding and release has been shown to function through an inward and outward alternating conformer known as a rocker-switch model (Nishima et al. 2014). The hydrophobicity of the drug binding clefts and highly conserved negatively charged residues share similar characteristics with other cationic biocide selective transporter families.

Cloned and characterized Enterobacterial MATE members include E. coli MdtK (Morita et al. 1992), Klebsiella pneumoniae KetM/MdtK (Ogawa et al. 2015), and Enterobacter cloacae EmmdR (He et al. 2011a), which all confer resistance to QAC antiseptics and DNA intercalating dyes as well as quinolone antimicrobials (Table 1) driven by $\mathrm{Na}^{+}$and/or $\mathrm{H}^{+}$motive force similar to NorM (Jin et al. 2014). E. cloacae EmmdR shows much higher sequence identity to $E$. coli MATE member $\mathrm{YeeO}$ than MdtK (Fig. 2), suggesting that two different biocide selective TolC-independent MATE members are present in Enterobacteriaceae. In Enterobacteriaceae, MATE genes are encoded chromosomally and have not been confidently identified from multidrug resistant plasmids yet according to BacNet (Pal et al. 2014) and GenBank searches); genes encoding MATE members often possess an alternative start codon, GTG, that may play a regulatory role in reducing its expression indicative of conditional regulation (Long et al. 2008; Ogawa et al. 2015). MATE homologue E. coli MdtK overexpression has been shown to rescue 8-oxoguaninerepair-deficient hypermutator phenotypes and protect cells against $\mathrm{H}_{2} \mathrm{O}_{2}$ damage, suggesting that NorM homologues may act as a guanine oxidation backup system when toxic metabolic reactive oxygen species build up (Guelfo et al. 2010). Since QAC biocides have demonstrated an ability to induce significant oxidative damage to cells, and many have complex chemical structures reminiscent of fluoroquinolones (as reviewed by (Buffet-Bataillon et al. 2016)), MATE protein biocide efflux may be a coincidental byproduct related to oxidative stress compounds rather than specific biocide resistance. In E. coli, MdtK and RND pump AcrAB were both shown to influence cell growth during stationary phase (Yang et al. 2006), potentially due to the secretion of metabolic quorum sensing molecules 
such as 4-quinolone that may influence cell-cell communication and biofilm formation (Nair et al. 2016). The fact that MATE members function as sodium-drug antiporters and regulate quorum sensing factor release, and confer protection against reactive oxygen species, suggests that their role is multifaceted and involved in protection and regulating cell metabolism, in addition to multidrug resistance.

\section{Proteobacterial Antimicrobial Compound Efflux (PACE) Family}

The newest addition to the efflux transporter proteins is the PACE family, which was discovered in Acinetobacter baumannii by Hassan et al. 2013, and named accordingly as Acinetobacter chlorhexidine efflux protein I (AceI) (Hassan et al. 2015b). As the name suggests, the PACE efflux proteins have specificity for chlorhexidine as well as other cationic membrane disrupting QAC antimicrobials such as, benzalkonium chloride and acriflavine (Table 1) (Hassan et al. 2015b). A. baumannii AceI efflux pumps were discovered from chlorhexidine shock induction experiments monitoring transcriptionally upregulated genes; chlorhexidine was selected for its frequent antiseptic usage in industrial and hospital settings (Hassan et al. 2013). PACE efflux pumps are predicted to function as a secondary active drug/ $\mathrm{H}^{+}$antiporter (Hassan et al. 2015b). Secondary structure predictions of AceI and its homologues indicate that these proteins are short in length (180 amino acids) and have two tandem bacterial transmembrane pair (BTP) domains (Fig. 3d) (Hassan et al. 2015a). AceI homologues also rely upon a negatively charged glutamate (A. baumannii E50; E. coli E22) residue in the first TMH domain (Fig. 2), which was shown to inhibit transport activity, but not drug binding, suggesting other as yet unidentified residues may be involved in chlorhexidine binding (Hassan et al. 2013). Although PACE family members are primarily identified from y-proteobacteria, they are not exclusively found in proteobacteria, there are also a few homologous members in the firmicutes Veillonella parvula, and likely in representatives of other phyla (Hassan et al. 2015a). In E. coli, there is an AceI homolog identified in the strains TW07793 and KTE84, which are flanked by transposase and phage insertion sequences, suggesting these PACE transporters were acquired laterally from related proteobacteria (Hassan et al. 2013). To date, PACE efflux proteins have only been identified in the domain Eubacteria demonstrating similarity to the SMR family of transporters. PACE family members may also be regulated by a general stress response mechanism (Hassan et al. 2013), but it remains unclear how similar the stress response is to other single component transporter families.

\section{Cation Diffusion Facilitator (CDF) Superfamily}

Cation Diffusion Facilitators (CDFs) represent a family of transporters in all three kingdoms of life that confer metal tolerance/resistance by efflux of zinc and heavy metal ions (Cubillas et al. 2013; Kolaj-Robin et al. 2015). Phylogenomic groupings of prokaryotic CDF family members are based on metal ion specificity (Cubillas et al. 2013), and thus far only one CDF member has demonstrated biocide resistance, $K$. pneumoniae chlorhexidine efflux protein A (CepA) (Fang et al. 2002), also annotated as ferrous iron efflux protein $\mathrm{F}$ (FieF/YiiP) due to its ability to relieve toxic concentrations of iron stress (Grass et al. 2005). The archetypical structural arrangement of the bacterial CDF protein family is based on the crystal structures of the zinc binding CDF member in E. coli FieF/YiiP (Lu and Fu 2007; Lu et al. 2009). E. coli FieF/YiiP forms a functional homodimer where each monomer has a modular two domain architecture in which both TMH domains form a hydrophobic cleft, and cytoplasmically exposed domains form a metal ion binding domain (Fig. 2) (Wei et al. 2004). Monomeric CDF protein arranges to form $6 \mathrm{TMH}$ with three domains: an N-terminal domain (NTD), histidine rich interconnecting loops (ILs), and 100 a.a. long C-terminal domain (CTD) arranging together to form a TMH and cytoplasmic domain that coordinates the metal ion transport from the cytoplasm (Fig. 3e) (Kolaj-Robin et al. 2015). Dimer stabilization and metal ion coordination is accomplished by conserved aspartate and histidine residues within the TMH domain of the E. coli FieF protein, TMH2 (D45, D49), and TM5 (H153, D157); as well as a number of hydrophobic cleft forming residues located in TMH2, TMH3, and TMH5; along with salt bridge forming aspartate and lysine residues located in TMH3 and cytoplasmic domains (Wei and Fu 2006; Fu 2010; Kolaj-Robin et al. 2015). Based on current structures of the E. coli YiiP (Lu and Fu 2007; Coudray et al. 2013), it is uncertain how chlorhexidine transport is accomplished by $K$. pneumoniae CepA, despite their high sequence identity (86\%) (Fang et al. 2002); nor is it clear if other FieF homologues can confer biocide resistance. FieF homologues are well represented in most pathogenic Enterobacterial species (Fig. 1b), suggesting that metal and chlorhexidine efflux may be important for pathogenicity. Two transport mechanism models are currently being validated (Kolaj-Robin et al. 2015). cepA genes are frequently detected in biocide resistant Klebseilla spp. isolates (Abuzaid et al. 2012; Naparstek et al. 2012; Rania et al. 2014), as well as in Enterobacter sp. (Ren et al. 2010) either chromosomally (Cubillas et al. 2013), or from multidrug resistant plasmids (Rania et al. 2014). cepA is commonly associated with other biocide selective efflux pump family members, most 
frequently SMR family qac genes (Azadpour et al. 2015), and/or MFS cmlA members (Naparstek et al. 2012). The association of toxic metal efflux pumps with efflux pumps conferring biocide resistance is not uncommon on mobile genetic elements (Gullberg et al. 2014; Wales and Davies 2015; Pal et al. 2015), as both toxic/heavy metals and biocides are used together as antiseptics in livestock and healthcare settings. Further examination of the potential biocide resistance conferred by FieF homologues will hopefully provide additional insights into the role they play in virulence, and antimicrobial/metal resistance in Enterobacteriaceae.

\section{Knowledge Gaps}

Many questions remain regarding the structure, function, and regulation of TolC-independent efflux pumps. Regarding functional considerations, how biocides are completely expelled from within the periplasm after single component efflux activity remains unclear. Do these pumps function with one or more multipartite systems, such as the AcrAB-TolC system as suggested from an E. coli study of combinatorial RND AcrAB, SMR emrE, and MFS mdfA gene deletions ( $\mathrm{Tal}$ and Schuldiner 2009)? Or is the expulsion of substrates across the outer membrane from the periplasm reliant on passive diffusion through one or more OMP? Evidence supporting specific OMP involvement has been demonstrated for SMR member EmrE, which demonstrated an association with OmpW to expel osmoprotectants and methyl viologen (Beketskaia et al. 2014). What roles do these efflux systems contribute to biofilms? QACs are frequently used to eradicate biofilms (McBain et al. 2004; Buffet-Bataillon et al. 2011), the presence of QAC resistant TolC-independent efflux pumps may indicate that these systems play a role in the establishment and maintenance of biofilm growth (Russell 2003; McBain et al. 2004; Houari and Di Martino 2007; Buffet-Bataillon et al. 2011; Soto 2013a). Therefore, single component efflux pumps may contribute to biofilm formations that are more difficult to treat in healthcare and industrial settings, making this an imperative area for future study.

The association of lipid modifications caused by biocide exposure and upregulated efflux activity is also present in biocide resistant Enterobacteriaceae. Most biocide resistance studies examine laboratory adapted strains that exhibit changes not only in efflux pump activity but also in lipid modifications which alter head group charge and fatty acid saturation (Braoudaki and Hilton 2004, 2005; Langsrud et al. 2004; Bore et al. 2007). Studies of SMR member EmrE suggest that efflux pump activity is regulated by lipids, specifically low abundance anionic phospholipid cardiolipin (Charalambous et al. 2008; Miller et al. 2009;
Dutta et al. 2014). Understanding the interconnectedness of biocides, lipids, and efflux pump proteins together, may help improve the design of specific efflux pump inhibitors.

With regards to function, the biocide concentrations that individual efflux pumps can confer resistance to may differ depending on how the cells are grown: the physiology of the cells (planktonic versus surface attached biofilm), the type of growth media used, and the background genotype of the bacterial strain used to measure minimum inhibitory concentration values attributed to specific pump activity [as reviewed by (Baugh et al. 2014; Blair and Piddock 2016)]. $E$. coli, being a reservoir for mobile genes in the environment (Szmolka and Nagy 2013), and a representative member of Enterobacteriaceae, make it an ideal candidate to study single component efflux pumps as a model organism. Considering many TolC-independent efflux pumps exhibit conditional activity that influences osmoregulation (SMR, MFS, and MATE), DNA repair (MATE), metal transport (CDF), and metabolite regulation (SMR, MFS, and MATE), these efflux systems likely have overlooked importance. Further insights into the nature of the stress response(s) involved in single component efflux system expression beyond standard laboratory growth conditions may help provide greater insights into conditional phenotypes conferred by these efflux pumps.

\section{Concluding Remarks}

The biocide selective transporter families focused on in this review are found in many pathogenic Gram-negative Enterobacteriaceae, and the fact that they may confer cross-resistance to other antimicrobials, highlights their clinical importance (Table 1). In addition to drug resistance, many of these TolC-independent efflux pumps contribute towards other physiological processes such as osmoregulation (SMR, MFS, and MATE), biofilms (SMR, MFS, and MATE), quorum sensing (MATE), tolerance to toxic metals (CDF) and reactive oxygen species (MATE); these features demonstrate the adaptability, and multifaceted function that are hallmarks of single component efflux pumps.

Single component efflux pump systems have been largely overlooked as compared to other well studied efflux families, such as multipartite RND pumps, however, their prevalence on mobile genetic elements, along with their frequent detection in healthcare and environmental Enterobacterial isolates, suggests that there is sufficient selective pressure to maintain and spread these efflux pumps to other systems. The selection for these single component efflux pumps may be perpetuated by the widespread overuse of antimicrobials, especially cationic antiseptics such as QACs, and the detection of these efflux pumps may be a 
marker for anthropogenic contamination of the environment with these antimicrobials; driving a shift towards decreased membrane permeability in Gram-negative bacilli. The recent ban of biocides from hand soaps by the US Food and Drug Administration (Sept. 2016), which includes triclosan, and many QAC antiseptics as well as even more stringent regulations imposed on the use and inclusion of biocides in commercial products by the European union over the last 10 years (Biocidal Products Regulation; https://ec.europa.eu/health/biocides/policy_ en), provide some hope that more responsible biocide regulations and stewardship may soon be on the global horizon. By reducing environmental biocide exposure, we may begin to reduce the selective pressure driving the spread and adaptation of these efflux systems towards biocides and antimicrobials.

Acknowledgements Funding for this work was provided by a Natural Sciences and Engineering Research Council Discovery operating grant to DCB.

Open Access This article is distributed under the terms of the Creative Commons Attribution 4.0 International License (http://crea tivecommons.org/licenses/by/4.0/), which permits unrestricted use, distribution, and reproduction in any medium, provided you give appropriate credit to the original author(s) and the source, provide a link to the Creative Commons license, and indicate if changes were made.

\section{References}

Abuzaid A, Hamouda A, Amyes SGBGB (2012) Klebsiella pneumoniae susceptibility to biocides and its association with cepA, qac $\Delta \mathrm{E}$ and qacE efflux pump genes and antibiotic resistance. J Hosp Infect 81:87-91. doi:10.1016/j.jhin.2012.03.003

Adler J, Lewinson O, Bibi E (2004) Role of a conserved membraneembedded acidic residue in the multidrug transporter MdfA. Biochemistry 43:518-525

Alcalde-Rico M, Hernando-Amado S, Blanco P, Martínez JL (2016) Multidrug efflux pumps at the crossroad between antibiotic resistance and bacterial virulence. Front, Microbiol, $\mathrm{p} 7$

Atiyeh BS, Dibo SA, Hayek SN (2009) Wound cleansing, topical antiseptics and wound healing. Int. Wound J. 6:420-430

Azadpour M, Nowroozi J, Goudarzi GR, Mahmoudvand H (2015) Presence of qacE $\Delta 1$ and cepA genes and susceptibility to a hospital biocide in clinical isolates of klebsiella pneumoniae in iran. Trop Biomed 32:109-115

Baugh S, Phillips CR, Ekanayaka AS et al (2014) Inhibition of multidrug efflux as a strategy to prevent biofilm formation. J Antimicrob Chemother 69:673-681

Bay DC, Turner RJ (2009) Diversity and evolution of the small multidrug resistance protein family. BMC Evol Biol 9:140. doi:10.1186/1471-2148-9-140

Bay DC, Turner RJ (2012) Small multidrug resistance protein EmrE reduces host $\mathrm{pH}$ and osmotic tolerance to metabolic quaternary cation osmoprotectants. J Bacteriol 194:5941-5948

Bay DC, Turner RJ (2016) Small Multidrug Resistance Efflux Pumps. Efflux-Mediated Antimicrob Resist Bact 1:45-71. doi:10.1007/ 978-3-319-39658-3_3
Bay DC, Rommens KL, Turner RJ (2008) Small multidrug resistance proteins: a multidrug transporter family that continues to grow. Biochim Biophys Acta 1778:1814-1838. doi:10.1016/j.bbamem. 2007.08.015

Bay DC, Budiman RA, Nieh M-P, Turner RJ (2010) Multimeric forms of the small multidrug resistance protein EmrE in anionic detergent. Biochim Biophys Acta 1798:526-535. doi:10.1016/j. bbamem.2009.12.017

Bay DC, Stremick CA, Slipski CJ, Turner RJ (2017) Secondary multidrug efflux pump mutants alter Escherichia coli biofilm growth in the presence of cationic antimicrobial compounds. Res Microbiol 168:208-221. doi:10.1016/j.resmic.2016.11.003

Beketskaia MS, Bay DC, Turner RJ (2014) Outer membrane protein OmpW participates with small multidrug resistance protein member EmrE in quaternary cationic compound efflux. J Bacteriol 196:1908-1914

Berger S, Alauzet C, Aissa N et al (2013) Characterization of a new blaOXA-48-carrying plasmid in Enterobacteriaceae. Antimicrob Agents Chemother 57:4064-4067. doi:10.1128/AAC.02550-12

Bischoff KM, White DG, Hume ME et al (2005) The chloramphenicol resistance gene cmlA is disseminated on transferable plasmids that confer multiple-drug resistance in swine Escherichia coli. FEMS Microbiol Lett 243:285-291

Bishop RE, Weiner JH (1993) Complementation of growth defect in an ampC deletion mutant of Escherichia coli. FEMS Microbiol Lett 114:349-354

Bishop RE, Penfold SS, Frost LS et al (1995) Stationary phase expression of a novel Escherichia coli outer membrane lipoprotein and its relationship with mammalian apolipoprotein D. Implications for the origin of lipocalins. J Biol Chem 270:23097-23103

Blair JM, Piddock LJ (2016) How to Measure Export via Bacterial Multidrug Resistance Efflux Pumps. MBio. doi:10.1128/mBio. 00840-16

Blair JM, Richmond GE, Piddock LJ (2014) Multidrug efflux pumps in Gram-negative bacteria and their role in antibiotic resistance. Futur Microbiol 9:1165-1177. doi:10.2217/fmb.14.66

Bohn C, Bouloc P (1998) The Escherichia coli cmlA gene encodes the multidrug efflux pump Cmr/MdfA and is responsible for isopropyl- $\beta$-D-thiogalactopyranoside exclusion and spectinomycin sensitivity. J Bacteriol 180:6072-6075

Bore E, Hebraud M, Chafsey I et al (2007) Adapted tolerance to benzalkonium chloride in Escherichia coli K-12 studied by transcriptome and proteome analyses. Microbiology 153:935-946

Bragg R, Van Der Westhuizen W, Lee J et al (2014) Infectious Diseases and Nanomedicine I. Adv Exp Med Biol 807:97-110. doi:10.1007/978-81-322-1777-0

Braoudaki M, Hilton AC (2004) Adaptive Resistance to Biocides in Salmonella enterica and Escherichia coli $\mathrm{O} 157$ and CrossResistance to Antimicrobial Agents. J Clin Microbiol 42:73-78. doi:10.1128/JCM.42.1.73-78.2004

Braoudaki M, Hilton AC (2005) Mechanisms of resistance in Salmonella enterica adapted to erythromycin, benzalkonium chloride and triclosan. Int $\mathbf{J}$ Antimicrob Agents 25:31-37. doi:10.1016/j.ijantimicag.2004.07.016

Brill S, Falk OS, Schuldiner S (2012) Transforming a drug/ $\mathrm{H}+$ antiporter into a polyamine importer by a single mutation. Proc Natl Acad Sci U S A 109:16894-16899

Buffet-Bataillon S, Branger B, Cormier M et al (2011) Effect of higher minimum inhibitory concentrations of quaternary ammonium compounds in clinical E. coli isolates on antibiotic susceptibilities and clinical outcomes. J Hosp Infect 79:141-146. doi:10.1016/j.jhin.2011.06.008

Buffet-Bataillon S, Tattevin P, Bonnaure-Mallet M, Jolivet-Gougeon A (2012) Emergence of resistance to antibacterial agents: the 
role of quaternary ammonium compounds-a critical review. Int J Antimicrob Agents 39:381-389

Buffet-Bataillon S, Tattevin P, Maillard J-Y et al (2016) Efflux pump induction by quaternary ammonium compounds and fluoroquinolone resistance in bacteria. Futur Microbiol 11:81-92. doi: $10.2217 / \mathrm{fmb} .15 .131$

Butler PJ, Ubarretxena-Belandia I, Warne T, Tate CG (2004) The Escherichia coli multidrug transporter EmrE is a dimer in the detergent-solubilised state. J Mol Biol 340:797-808

Chapman JS (2003a) Biocide resistance mechanisms. Int Biodeterior Biodegrad 51:133-138. doi:10.1016/S0964-8305(02)00097-5

Chapman JS (2003b) Disinfectant resistance mechanisms, crossresistance, and co-resistance. In: International Biodeterioration and Biodegradation. pp 271-276

Charalambous K, Miller D, Curnow P, Booth PJ (2008) Lipid bilayer composition influences small multidrug transporters. BMC Biochem 9:31

Chen J, Morita Y, Huda MN et al (2002) VmrA, a member of a novel class of $\mathrm{Na}(+)$-coupled multidrug efflux pumps from Vibrio parahaemolyticus. J Bacteriol 184:572-576

Chen YJ, Pornillos O, Lieu S et al (2007) X-ray structure of EmrE supports dual topology model. Proc Natl Acad Sci U S A 104:18999-19004

Chung YJ, Saier MH Jr (2002) Overexpression of the Escherichia coli sugE gene confers resistance to a narrow range of quaternary ammonium compounds. J Bacteriol 184:2543-2545

Coudray N, Valvo S, Hu M et al (2013) Inward-facing conformation of the zinc transporter YiiP revealed by cryoelectron microscopy. Proc Natl Acad Sci 110:2140-2145. doi:10.1073/pnas. 1215455110

Cruz A, Micaelo N, Felix V et al (2013) sugE: A gene involved in tributyltin (TBT) resistance of Aeromonas molluscorum Av27. J Gen Appl Microbiol 59:39-47

Cubillas C, Vinuesa P, Tabche ML, García-de los Santos A (2013) Phylogenomic analysis of Cation Diffusion Facilitator proteins uncovers $\mathrm{Ni} 2+/ \mathrm{Co} 2+$ transporters. Metallomics 5:1634. doi: $10.1039 / \mathrm{c} 3 \mathrm{mt} 00204 \mathrm{~g}$

Drew D, Sjostrand D, Nilsson J et al (2002) Rapid topology mapping of Escherichia coli inner-membrane proteins by prediction and PhoA/GFP fusion analysis. Proc Natl Acad Sci U S A 99:2690-2695

Du D, Wang Z, James NR et al (2014) Structure of the AcrAB-TolC multidrug efflux pump. Nature 509:512-515. doi:10.1038/ nature 13205

Du D, van Veen HW, Murakami S et al (2015) Structure, mechanism and cooperation of bacterial multidrug transporters. Curr. Opin. Struct, Biol, p 33

Dutta S, Morrison EA, Henzler-Wildman KA (2014) EmrE dimerization depends on membrane environment. Biochim Biophys Acta 1838:1817-1822

Edgar R, Bibi E (1997) MdfA, an Escherichia coli multidrug resistance protein with an extraordinarily broad spectrum of drug recognition. J Bacteriol 179:2274-2280

Fang CT, Chen HC, Chuang YP et al (2002) Cloning of a cation efflux pump gene associated with chlorhexidine resistance in Klebsiella pneumoniae. Antimicrob Agents Chemother 46:2024-2028. doi:10.1128/AAC.46.6.2024-2028.2002

Fernandez L, Hancock RE (2012) Adaptive and mutational resistance: role of porins and efflux pumps in drug resistance. Clin Microbiol Rev 25:661-681

Fraud S, Campigotto AJ, Chen Z, Poole K (2008) MexCD-OprJ multidrug efflux system of Pseudomonas aeruginosa: involvement in chlorhexidine resistance and induction by membranedamaging agents dependent upon the $\mathrm{Alg} \mathrm{U}$ stress response sigma factor. Antimicrob Agents Chemother 52:4478-4482. doi:10. 1128/AAC.01072-08
Fu D (2010) Zinc Transporter YiiP Escherichia coli. Handb Met. doi:10.1002/0470028637.met286

Gaze WH, Abdouslam N, Hawkey PM, Wellington EM (2005) Incidence of class 1 integrons in a quaternary ammonium compound-polluted environment. Antimicrob Agents Chemother 49:1802-1807

Gaze WH, Zhang L, Abdouslam NA et al (2011) Impacts of anthropogenic activity on the ecology of class 1 integrons and integron-associated genes in the environment. ISME J 5:1253-1261

Gaze WH, Krone SM, Larsson DG et al (2013) Influence of humans on evolution and mobilization of environmental antibiotic resistome. Emerg Infect Dis. doi:10.3201/eid1907.120871

Gebel J, Exner M, French G, et al (2013) The role of surface disinfection in infection prevention. GMS Hyg Infect Control 8:Doc10. doi: 10.3205/dgkh000210

Gertz EM, Yu YK, Agarwala R et al (2006) Composition-based statistics and translated nucleotide searches: improving the TBLASTN module of BLAST. BMC Biol 4:41

Gilbert P, McBain AJ (2003) Potential impact of increased use of biocides in consumer products on prevalence of antibiotic resistance. Clin Microbiol Rev 16:189-208. doi:10.1128/CMR. 16.2.189

Gilbert P, Moore LE (2005) Cationic antiseptics: diversity of action under a common epithet. J Appl Microbiol 99:703-715

Gillings M, Boucher Y, Labbate M et al (2008) The evolution of Class 1 Integrons and the rise of antibiotic resistance. J Bacteriol 190:5095-5100

Gillings MR, Holley MP, Stokes HW (2009) Evidence for dynamic exchange of qac gene cassettes between class 1 integrons and other integrons in freshwater biofilms. FEMS Microbiol Lett 296:282-288

Gnanadhas DP, Marathe SA, Chakravortty D (2013) Biocides resistance, cross-resistance mechanisms and assessment. Expert Opin Investig Drugs 22:191-206. doi:10.1517/13543784.2013. 748035

Grass G, Otto M, Fricke B et al (2005) FieF (YiiP) from Escherichia coli mediates decreased cellular accumulation of iron and relieves iron stress. Arch Microbiol 183:9-18. doi:10.1007/ s00203-004-0739-4

Guelfo JR, Rodriguez-Rojas A, Matic I, Blazquez J (2010) A MATEfamily efflux pump rescues the Escherichia coli 8-oxoguaninerepair-deficient mutator phenotype and protects against $\mathrm{H}(2) \mathrm{O}(2)$ killing. PLoS Genet 6:e1000931. doi:10.1371/journal.pgen. 1000931

Gullberg E, Albrecht LM, Karlsson C et al (2014) Selection of a Multidrug Resistance Plasmid by Sublethal Levels of Antibiotics and Heavy Metals. MBio. doi:10.1128/mBio.01918-14

Hassan KA, Jackson SM, Penesyan A et al (2013) Transcriptomic and biochemical analyses identify a family of chlorhexidine efflux proteins. Proc Natl Acad Sci. doi:10.1073/pnas. 1317052110

Hassan KA, Elbourne LDH, Li L et al (2015a) An ace up their sleeve: a transcriptomic approach exposes the AceI efflux protein of Acinetobacter baumannii and reveals the drug efflux potential hidden in many microbial pathogens. Front Microbiol. doi:10. 3389/fmicb. 2015.00333

Hassan KA, Liu Q, Henderson PJF, Paulsen IT (2015b) Homologs of the Acinetobacter baumannii acei transporter represent a new family of bacterial multidrug efflux systems. MBio. doi:10.1128/ mBio.01982-14

He X, Szewczyk P, Karyakin A et al (2010) Structure of a cationbound multidrug and toxic compound extrusion transporter. Nature 467:991-994. doi:10.1038/nature09408

He GX, Thorpe C, Walsh D et al (2011a) EmmdR, a new member of the MATE family of multidrug transporters, extrudes quinolones 
from Enterobacter cloacae. Arch Microbiol 193:759-765. doi:10.1007/s00203-011-0738-1

He GX, Zhang C, Crow RR et al (2011b) SugE, a new member of the SMR family of transporters, contributes to antimicrobial resistance in Enterobacter cloacae. Antimicrob Agents Chemother 55:3954-3957

Hegde NV, Kariyawasam S, DebRoy C (2016) Comparison of antimicrobial resistant genes in chicken gut microbiome grown on organic and conventional diet. Vet Anim Sci 1-2:9-14. doi:10.1016/j.vas.2016.07.001

Hegstad K, Langsrud S, Lunestad BT et al (2010) Does the wide use of quaternary ammonium compounds enhance the selection and spread of antimicrobial resistance and thus threaten our health? Microb Drug Resist 16:91-104. doi:10.1089/mdr.2009.0120

Heng J, Zhao Y, Liu M et al (2015) Substrate-bound structure of the E. coli multidrug resistance transporter MdfA. Cell Res 25:1060-1073. doi:10.1038/cr.2015.94

Heuer H, Szczepanowski R, Schneiker S et al (2004) The complete sequences of plasmids $\mathrm{pB} 2$ and $\mathrm{pB} 3$ provide evidence for a recent ancestor of the IncP-1beta group without any accessory genes. Microbiology 150:3591-3599

Higashi K, Ishigure H, Demizu R et al (2008) Identification of a spermidine excretion protein complex (MdtJI) in Escherichia coli. J Bacteriol 190:872-878

Hirsch T, Limoochi-Deli S, Lahmer A et al (2011) Antimicrobial activity of clinically used antiseptics and wound irrigating agents in combination with wound dressings. Plast Reconstr Surg 127:1539-1545. doi:10.1097/PRS.0b013e318208d00f

Hofmann K, Stoffel W (1993) TMbase-a database of membrane spanning proteins segments. Biol Chem Hoppe Seyler 374:166

Hongo E, Morimyo M, Mita K et al (1994) The methyl viologenresistance-encoding gene smvA of Salmonella typhimurium. Gene 148:173-174

Houari A, Di Martino P (2007) Effect of chlorhexidine and benzalkonium chloride on bacterial biofilm formation. Lett Appl Microbiol 45:652-656

Hvorup RN, Winnen B, Chang AB et al (2003) The multidrug/ oligosaccharidyl-lipid/polysaccharide (MOP) exporter superfamily. Eur J Biochem 270:799-813

Ishikawa S, Matsumura Y, Yoshizako F, Tsuchido T (2002) Characterization of a cationic surfactant-resistant mutant isolated spontaneously from Escherichia coli. J Appl Microbiol 92:261-268. doi:10.1046/j.1365-2672.2002.01526.x

Jack DL, Yang NM, Saier MH Jr (2001) The drug/metabolite transporter superfamily. Eur J Biochem 268:3620-3639

Jagannadham MV, Chattopadhyay MK (2015) Role of outer membrane vesicles of bacteria. Resonance 20:711-725. doi:10.1007/ s12045-015-0228-x

Jin Y, Nair A, Van Veen HW (2014) Multidrug transport protein NorM from Vibrio cholerae simultaneously couples to sodiumand proton-motive force. J Biol Chem. doi:10.1074/jbc.M113. 546770

Kazama H, Hamashima H, Sasatsu M, Arai T (1999) Characterization of the antiseptic-resistance gene qacE delta 1 isolated from clinical and environmental isolates of Vibrio parahaemolyticus and Vibrio cholerae non-O1. FEMS Microbiol Lett 174:379-384

Kikukawa T, Miyauchi S, Araiso T et al (2007) Anti-parallel membrane topology of two components of EbrAB, a multidrug transporter. Biochem Biophys Res Commun 358:1071-1075

Kolaj-Robin O, Russell D, Hayes KA et al (2015) Cation diffusion facilitator family: structure and function. FEBS Lett 589:1283-1295. doi:10.1016/j.febslet.2015.04.007

Korkhov VM, Tate CG (2009) An emerging consensus for the structure of EmrE. Acta Crystallogr D 65:186-192

Krogh A, Larsson B, von Heijne G, Sonnhammer EL (2001) Predicting transmembrane protein topology with a hidden
Markov model: application to complete genomes. J Mol Biol 305:567-580

Kücken D, Feucht H, Kaulfers P (2000) Association of qacE and qacEDelta1 with multiple resistance to antibiotics and antiseptics in clinical isolates of Gram-negative bacteria. FEMS Microbiol Lett 183:95-98

Kulkarni HM, Nagaraj R, Jagannadham MV (2015) Protective role of E. coli outer membrane vesicles against antibiotics. Microbiol Res 181:1-7. doi:10.1016/j.micres.2015.07.008

Kumar S, Floyd JT, He G, Varela MF (2013a) Bacterial antimicrobial efflux pumps of the MFS and MATE transporter families: a review. Recent Res Dev Antimicrob Agents Chemother 7:1-21

Kumar S, Mukherjee MM, Varela MF (2013b) Modulation of bacterial multidrug resistance efflux pumps of the major facilitator superfamily. Int J Bacteriol. doi:10.1155/2013/204141

Kuroda T, Tsuchiya T (2009) Multidrug efflux transporters in the MATE family. Biochim Biophys Acta 1794:763-768

Langsrud S, Sundheim G, Holck AL (2004) Cross-resistance to antibiotics of Escherichia coli adapted to benzalkonium chloride or exposed to stress-inducers. J Appl Microbiol 96:201-208

Levy SB (2002) Active efflux, a common mechanism for biocide and antibiotic resistance. Symp Ser Soc Appl Microbiol 92:65S-71S. doi:10.1046/j.1365-2672.92.5s1.4.x

Lewinson O, Padan E, Bibi E (2004) Alkalitolerance: a biological function for a multidrug transporter in $\mathrm{pH}$ homeostasis. Proc Natl Acad Sci USA 101:14073-14078

Li X, Nikaido H (2004) Efflux-mediated drug resistance in bacteria. Drugs 64:159-204

Li X-Z, Plésiat P, Nikaido H (2015) The challenge of efflux-mediated antibiotic resistance in Gram-negative bacteria. Clin Microbiol Rev 28:337-418. doi:10.1128/CMR.00117-14

Lloris-Garcera P, Bianchi F, Slusky JS et al (2012) Antiparallel dimers of the small multidrug resistance protein EmrE are more stable than parallel dimers. J Biol Chem 287:26052-26059

Long F, Rouquette-Loughlin C, Shafer WM, Yu EW (2008) Functional cloning and characterization of the multidrug efflux pumps NorM from Neisseria gonorrhoeae and YdhE from Escherichia coli. Antimicrob Agents Chemother 52:3052-3060. doi:10.1128/AAC.00475-08

Lu M, Fu D (2007) Structure of the zinc transporter YiiP. Science 80(317):1746-1748. doi:10.1126/science.1143748

Lu M, Chai J, Fu D (2009) Structural basis for autoregulation of the zinc transporter YiiP. Nat Struct Mol Biol 16:1063-1067. doi:10. 1038/nsmb.1662

Lu M, Symersky J, Radchenko M et al (2013) Structures of a Na+ coupled, substrate-bound MATE multidrug transporter. Proc Natl Acad Sci 110:2099-2104. doi:10.1073/pnas.1219901110

Maillard JY (2002) Bacterial target sites for biocide action. Symp Ser Soc Appl Microbiol 92:16S-27S

Maillard J-Y (2005) Antimicrobial biocides in the healthcare environment: efficacy, usage, policies, and perceived problems. Ther Clin Risk Manag 1:307-320

Marquez B (2005) Bacterial efflux systems and efflux pumps inhibitors. Biochimie 87:1137-1147

Matsumura K, Furukawa S, Ogihara H, Morinaga Y (2011) Roles of multidrug efflux pumps on the biofilm formation of Escherichia coli $\mathrm{K}-12$. Biocontrol Sci 16:69-72

Mazel D, Dychinco B, Webb VA, Davies J (2000) Antibiotic resistance in the ECOR collection: integrons and identification of a novel aad gene. Antimicrob Agents Chemother 44:1568-1574

McBain AJ, Ledder RG, Moore LE et al (2004) Effects of quaternaryammonium-based formulations on bacterial community dynamics and antimicrobial susceptibility. Appl Env Microbiol 70:3449-3456

McDonnell G, Russell AD (1999) Antiseptics and disinfectants: activity, action, and resistance. Clin Microbiol Rev 12:147-179 
McMurry LM, Oethinger M, Levy SB (1998) Overexpression of marA, soxS, or acrAB produces resistance to triclosan in laboratory and clinical strains of Escherichia coli. FEMS Microbiol Lett 166:305-309

Miller D, Charalambous K, Rotem D et al (2009) In vitro unfolding and refolding of the small multidrug transporter EmrE. J Mol Biol 393:815-832

Mima T, Joshi S, Gomez-Escalada M, Schweizer HP (2007) Identification and characterization of TriABC-OpmH, a triclosan efflux pump of Pseudomonas aeruginosa requiring two membrane fusion proteins. J Bacteriol 189:7600-7609. doi:10.1128/ JB.00850-07

Minato Y, Shahcheraghi F, Ogawa W et al (2008) Functional gene cloning and characterization of the SsmE multidrug efflux pump from Serratia marcescens. Biol Pharm Bull 31:516-519. doi:10. 1248/bpb.31.516

Mine T, Morita Y, Kataoka A et al (1998) Evidence for chloramphenicol/H+ antiport in Cmr (MdfA) system of Escherichia coli and properties of the antiporter. J Biochem 124:187-193. doi:10. 1093/oxfordjournals.jbchem.a022078

Mishra MN, Daniels L (2013) Characterization of the MSMEG_2631 gene (mmp) encoding a multidrug and toxic compound extrusion (MATE) family protein in Mycobacterium smegmatis and exploration of its polyspecific nature using biolog phenotype microarray. J Bacteriol 195:1610-1621. doi:10.1128/JB.0172412

Morita N, Gotoh M, Okajima N et al (1992) Both the anaerobic pathway and aerobic desaturation are involved in the synthesis of unsaturated fatty acids in Vibrio sp. strain ABE-1. FEBS Lett 297:9-12

Morita Y, Kodama K, Shiota S et al (1998) NorM, a putative multidrug efflux protein, of Vibrio parahaemolyticus and its homolog in Escherichia coli. Antimicrob Agents Chemother 42:1778-1782

Morrison EA, DeKoster GT, Dutta S et al (2011) Antiparallel EmrE exports drugs by exchanging between asymmetric structures. Nature 481:45-50

Morrison EA, Robinson AE, Liu Y, Henzler-Wildman KA (2015) Asymmetric protonation of EmrE. J Gen Physiol 146:445-461. doi:10.1085/jgp.201511404

Nair AV, Lee KW, Van Veen HW (2016) Structural and functional landscape of MFS and MATE efflux pumps. In: Li X-Z, Elkins CA, Zgurskaya HI (eds) Efflux-mediated antimicrobial resistance in bacteria: mechanisms, regulation and clinical implications, 1st edn. Springer, New York, pp 29-44

Naparstek L, Carmeli Y, Chmelnitsky I et al (2012) Reduced susceptibility to chlorhexidine among extremely-drug-resistant strains of Klebsiella pneumoniae. J Hosp Infect 81:15-19. doi:10.1016/j.jhin.2012.02.007

Naroditskaya V, Schlosser MJ, Fang NY, Lewis K (1993) An E. coli gene emrD is involved in adaptation to low energy shock. Biochem Biophys Res Commun 196:803-809

Nishima W, Tanaka Y, Ishitani R et al (2014) Drug extrusion process of mate multidrug efflux transporter revealed by molecular dynamics simulations. Biophys J 106:801a. doi:10.1016/j.bpj. 2013.11.4392

Nishino K, Yamaguchi A (2001) Analysis of a complete library of putative drug transporter genes in Escherichia coli. J Bacteriol 183:5803-5812

Nishino K, Yamada J, Hirakawa H et al (2003) Roles of TolCdependent multidrug transporters of Escherichia coli in resistance to beta-lactams. Antimicrob Agents Chemother 47:3030-3033

Ogawa W, Koterasawa M, Kuroda T, Tsuchiya T (2006) KmrA multidrug efflux pump from Klebsiella pneumoniae. Biol Pharm Bull 29:550-553. doi:10.1248/bpb.29.550
Ogawa W, Minato Y, Dodan H et al (2015) Characterization of MATE-type multidrug efflux pumps from Klebsiella pneumoniae MGH78578. PLoS ONE 10:1-19. doi:10.1371/journal. pone. 0121619

Omasits U, Ahrens CH, Muller S, Wollscheid B (2014) Protter: interactive protein feature visualization and integration with experimental proteomic data. Bioinformatics 30:884-886

Omote H, Hiasa M, Matsumoto T et al (2006) The MATE proteins as fundamental transporters of metabolic and xenobiotic organic cations. Trends Pharmacol Sci 27:587-593. doi:10.1016/j.tips. 2006.09.001

Opperman TJ, Nguyen ST (2015) Recent advances toward a molecular mechanism of efflux pump inhibition. Front, Microbiol, p 6

Orelle C, Jault J (2016) Structures and transport mechanisms of the ABC efflux pumps. In: Efflux-mediated antimicrobial resistance in bacteria. pp 73-98

Otter JA, Vickery K, Walker JT et al (2015) Surface-attached cells, biofilms and biocide susceptibility: implications for hospital cleaning anddisinfection. J Hosp Infect 89:16-27

Pal C, Bengtsson-Palme J, Rensing C et al (2014) BacMet: antibacterial biocide and metal resistance genes database. Nucleic Acids Res 42:D737-D743

Pal C, Bengtsson-Palme J, Kristiansson E, Larsson DGJ (2015) Cooccurrence of resistance genes to antibiotics, biocides and metals reveals novel insights into their co-selection potential. BMC Genomics 16:964. doi:10.1186/s12864-015-2153-5

Pastrana-Carrasco J, Garza-Ramos JU, Barrios H et al (2012) QacEdelta1 gene frequency and biocide resistance in extendedspectrum beta-lactamase producing enterobacteriaceae clinical isolates. Rev Invest Clin 64:535-540

Paulsen IT, Littlejohn TG, Radstrom P et al (1993) The $3^{\prime}$ conserved segment of integrons contains a gene associated with multidrug resistance to antiseptics and disinfectants. Antimicrob Agents Chemother 37:761-768

Piddock LJV (2006) Multidrug-resistance efflux pumps—not just for resistance. Nat Rev Microbiol 4:629-636. doi:10.1038/ nrmicro1464

Ping Y, Ogawa W, Kuroda T, Tsuchiya T (2007) Gene cloning and characterization of KdeA, a multidrug efflux pump from Klebsiella pneumoniae. Biol Pharm Bull 30:1962-1964. doi:10.1248/bpb.30.1962

Ploy MC, Courvalin P, Lambert T (1998) Characterization of In40 of Enterobacter aerogenes BM2688, a class 1 integron with two new gene cassettes, cmlA2 and qacF. Antimicrob Agents Chemother 42:2557-2563

Poole K (2002) Mechanisms of bacterial biocide and antibiotic resistance. J Appl Microbiol 92:55S-64S. doi:10.1046/j.13652672.92.5s1.8.x

Poole K (2014a) Stress responses as determinants of antimicrobial resistance in Pseudomonas aeruginosa: multidrug efflux and more. Can J Microbiol 60:783-791. doi:10.1139/cjm-2014-0666

Poole K (2014b) Efflux-mediated antimicrobial resistance. In: antibiotic discovery and development. pp 349-395

Quistgaard EM, Löw C, Guettou F, Nordlund P (2016) Understanding transport by the major facilitator superfamily (MFS): structures pave the way. Nat Rev Mol Cell Biol 17:123-132. doi:10.1038/ nrm. 2015.25

Rania K, Mohamed M, Waheed H, Nader N (2014) Efflux pump genes and chlorhexidine resistance: clue for Klebsiella pneumoniae infections in intensive care units, Egypt. Afr J Microbiol Res 8:2162-2167. doi:10.5897/AJMR2014.6656

Rapp M, Drew D, Daley DO et al (2004) Experimentally based topology models for E. coli inner membrane proteins. Protein Sci 13:937-945 
Reddy VS, Shlykov MA, Castillo R et al (2012) The major facilitator superfamily (MFS) revisited. FEBS J 279:2022-2035. doi:10. 1111/j.1742-4658.2012.08588.x

Ren Y, Ren Y, Zhou Z et al (2010) Complete genome sequence of Enterobacter cloacae subsp. cloacae type strain ATCC 13047. J Bacteriol 192:2463-2464. doi:10.1128/JB.00067-10

Ripley B (2017) Package "boot”, pp 1-28

Rowbury RJ (2003) Introduction. Responses to weak acids, alkalinisation, biocides, UV irradiation, and toxic metal ions. Sci Prog $86: 235-244$

Russell AD (2000) Do biocides select for antibiotic resistance? J Pharm Pharmacol 52:227-233. doi:10.1211/ 0022357001773742

Russell AD (2003) Biocide use and antibiotic resistance: the relevance of laboratory findings to clinical and environmental situations. Lancet Infect Dis 3:794-803

Saidijam M, Benedetti G, Ren Q et al (2006) Microbial drug efflux proteins of the major facilitator superfamily. Curr Drug Targets 7:793-811

Saier MH Jr (2001) Evolution of transport proteins. Genet Eng 23:1-10

Saier MH Jr, Paulsen IT (2001) Phylogeny of multidrug transporters. Semin Cell Dev Biol 12:205-213. doi:10.1006/scdb.2000.0246

Saier MH, Reddy VS, Tsu BV et al (2016) The transporter classification database (TCDB): recent advances. Nucleic Acids Res. doi:10.1093/nar/gkv1103

Santiviago CA, Fuentes JA, Bueno SM et al (2002) The Salmonella enterica sv. Typhimurium smvA, yddG and ompD (porin) genes are required for the efficient efflux of methyl viologen. Mol Microbiol 46:687-698

Schluter A, Heuer H, Szczepanowski R et al (2005) Plasmid pB8 is closely related to the prototype IncP-1beta plasmid R751 but transfers poorly to Escherichia coli and carries a new transposon encoding a small multidrug resistance efflux protein. Plasmid $54: 135-148$

Schuldiner S (2010) Parallel or antiparallel, who cares? Science 80(328): 1

Shahcheraghi F, Minato Y, Chen J et al (2007) Molecular cloning and characterization of a multidrug efflux pump, SmfY, from Serratia marcescens. Biol Pharm Bull 30:798-800. doi:10. 1248/bpb. 30.798

Sheldon AT Jr (2005) Antiseptic "resistance": real or perceived threat? Clin Infect Dis 40:1650-1656

Sigal N, Molshanski-Mor S, Bibi E (2006) No single irreplaceable acidic residues in the Escherichia coli secondary multidrug transporter MdfA. J Bacteriol 188:5635-5639. doi:10.1128/JB. 00422-06

Sigal N, Fluman N, Siemion S, Bibi E (2009) The secondary multidrug/proton antiporter MdfA tolerates displacements of an essential negatively charged side chain. J Biol Chem 284:6966-6971

Sivaraman S, Sullivan TJ, Johnson F et al (2004) Inhibition of the bacterial enoyl reductase FabI by triclosan: a structure-reactivity analysis of FabI inhibition by triclosan analogues. J Med Chem 47:509-518. doi:10.1021/jm030182i

Son MS, Del Castilho C, Duncalf KA et al (2003) Mutagenesis of SugE, a small multidrug resistance protein. Biochem Biophys Res Commun 312:914-921

Soto SM (2013) Role of efflux pumps in the antibiotic resistance of bacteria embedded in a biofilm. Virulence 4:223-229

Stavri M, Piddock LJ, Gibbons S (2007) Bacterial efflux pump inhibitors from natural sources. J Antimicrob Chemother 59:1247-1260

Stecher B, Denzler R, Maier L et al (2012) Gut inflammation can boost horizontal gene transfer between pathogenic and commensal Enterobacteriaceae. Proc Natl Acad Sci 109:1269-1274. doi:10.1073/pnas.1113246109

Steiner-Mordoch S, Soskine M, Solomon D et al (2008) Parallel topology of genetically fused EmrE homodimers. EMBO J 27:17-26

Su J, Shi L, Yang L et al (2006) Analysis of integrons in clinical isolates of Escherichia coli in China during the last six years. FEMS Microbiol Lett 254:75-80

Sulavik MC, Houseweart C, Cramer C et al (2001) Antibiotic susceptibility profiles of Escherichia coli strains lacking multidrug efflux pump genes. Antimicrob Agents Chemother 45:1126-1136. doi:10.1128/AAC.45.4.1126-1136.2001

Sun J, Deng Z, Yan A (2014) Bacterial multidrug efflux pumps: mechanisms, physiology and pharmacological exploitations. Biochem Biophys Res Commun 453:254-267

Szmolka A, Nagy B (2013) Multidrug resistant commensal Escherichia coli in animals and its impact for public health. Front Microbiol 4:258

Tal N, Schuldiner S (2009) A coordinated network of transporters with overlapping specificities provides a robust survival strategy. Proc Natl Acad Sci USA 106:9051-9056

Tanabe M, Szakonyi G, Brown KA et al (2009) The multidrug resistance efflux complex, EmrAB from Escherichia coli forms a dimer in vitro. Biochem Biophys Res Commun 380:338-342. doi:10.1016/j.bbrc.2009.01.081

Tegos GP, Haynes M, Strouse JJ et al (2011) Microbial efflux pump inhibition: tactics and strategies. Curr Pharm Des 17:1291-1302

Tezel T, Pavlostathis SG (2011) Role of quaternary ammonium compounds on antimicrobial resistance in the environment. In: Keen PL, Montforts MHMM (eds) Antimicrobial resistance in the environment, 1st edn. Wiley, Hoboken, pp 349-387

Tumah HN (2009) Bacterial biocide resistance. J Chemother 21:5-15

Van Boeckel TP, Gandra S, Ashok A et al (2014) Global antibiotic consumption 2000 to 2010: an analysis of national pharmaceutical sales data. Lancet Infect Dis 14:742-750

Villagra NA, Hidalgo AA, Santiviago CA et al (2008) SmvA, and not $\mathrm{AcrB}$, is the major efflux pump for acriflavine and related compounds in Salmonella enterica serovar Typhimurium. J Antimicrob Chemother 62:1273-1276. doi:10.1093/jac/dkn407

Wales A, Davies R (2015) Co-selection of resistance to antibiotics, biocides and heavy metals, and its relevance to foodborne pathogens. Antibiotics 4:567-604. doi:10.3390/antibiotics4040567

Wand ME, Bock LJ, Bonney LC, Sutton JM (2017) Mechanisms of increased resistance to chlorhexidine and cross-resistance to colistin following exposure of Klebsiella pneumoniae clinical isolates to chlorhexidine. Antimicrob Agents Chemother 61:1-31. doi:10.1128/AAC.01162-16

Wang X, Wood TK (2016) Cryptic prophages as targets for drug development. Drug Resist Updat 27:30-38. doi:10.1016/j.drup. 2016.06.001

Wang C, Zhan Q, Mi Z et al (2008) Distribution of the antisepticresistance gene qacEDelta1 in 283 clinical isolates of Gramnegative bacteria in China. J Hosp Infect 69:394-396

Wang Z, Fan G, Hryc CF et al (2017) An allosteric transport mechanism for the AcrAB-TolC multidrug efflux pump. Elife. doi:10.7554/eLife.24905

Waterhouse AM, Procter JB, Martin DM et al (2009) Jalview version 2-a multiple sequence alignment editor and analysis workbench. Bioinformatics 25:1189-1191

Webber MA, Randall LP, Cooles S et al (2008) Triclosan resistance in Salmonella enterica serovar Typhimurium. J Antimicrob Chemother 62:83-91. doi:10.1093/jac/dkn137

Wei Y, Fu D (2006) Binding and transport of metal ions at the dimer interface of the Escherichia coli metal transporter YiiP. J Biol Chem 281:23492-23502. doi:10.1074/jbc.M602254200 
Wei Y, Li H, Fu D (2004) Oligomeric state of the Escherichia coli metal transporter YiiP. J Biol Chem 279:39251-39259. doi:10. 1074/jbc.M407044200

Yan N (2013) Structural advances for the major facilitator superfamily (MFS) transporters. Trends Biochem Sci 38:151-159

Yang S, Lopez CR, Zechiedrich EL (2006) Quorum sensing and multidrug transporters in Escherichia coli. Proc Natl Acad Sci 103:2386-2391. doi:10.1073/pnas.0502890102

Yin Y (2006) Structure of the multidrug transporter EmrD from Escherichia coli. Science 80(312):741-744. doi:10.1126/ science. 1125629

Zgurskaya HI, Krishnamoorthy G, Ntreh A, Lu S (2011) Mechanism and function of the outer membrane channel TolC in multidrug resistance and physiology of enterobacteria. Front, Microbiol, p 2
Zhang X, Wright SH (2009) MATE1 has an external COOH terminus, consistent with a 13-helix topology. Am J Physiol Renal Physiol 297:F263-F271. doi:10.1152/ajprenal.00123.2009

Zhang C, Cui F, Zeng GM et al (2015) Quaternary ammonium compounds (QACs): a review on occurrence, fate and toxicity in the environment. Sci Total Environ 518-519:352-362. doi:10. 1016/j.scitotenv.2015.03.007

Zhang A, He X, Meng Y et al (2016) Antibiotic and disinfectant resistance of Escherichia coli isolated from retail meats in Sichuan, China. Microb Drug Resist 22:80-87. doi:10.1089/mdr. 2015.0061

Zou L, Meng J, McDermott PF et al (2014) Presence of disinfectant resistance genes in Escherichia coli isolated from retail meats in the USA. J Antimicrob Chemother 69:2644-2649 